\title{
Interaction of bending and axial load for ferritic stainless steel RHS columns
}

\author{
I. Arrayago, F. Picci, E. Mirambell and E. Real
}

Department of Construction Engineering, Universitat Politècnica de Catalunya, Barcelona, Spain

Corresponding author: I. Arrayago, C/ Jordi Girona 1-3, C1 Building (207), Barcelona 08034, Spain. Tel: +34 934054156; Fax: +34 934054135, e-mail: itsaso.arrayago@upc.edu

\begin{abstract}
Stainless steels are ideal for sustainable structural performances due to their excellent corrosion resistance, appropriate mechanical properties, aesthetic appearance and easy maintenance. However, the nonlinear behaviour and strain-hardening effects characterizing these materials make them different from carbon steel and some specific guidance is necessary. Although some investigations regarding the behaviour of stainless steel beam-columns subjected to combined compression and bending moment have already been published, most of them are based on the most commonly used austenitic and duplex grades. Hence, the work presented in this paper deals with the flexural buckling resistance of ferritic stainless steel RHS and SHS columns subjected to combined loading. The assessment of several design approaches codified in EN1993-1-4 and proposed in the literature has been conducted by comparing numerical results with the predicted ultimate capacities. The partial safety factor $\gamma_{M 1}$ currently coded in EN19931-4 has been found to provide unsafe ultimate flexural buckling resistance predictions and new coefficients for the $k$ interaction factor for ferritic RHS and SHS elements are proposed.
\end{abstract}

\section{KEYWORDS}

beam-columns, combined loading, ferritic stainless steel, interaction expressions 


\section{HIGHLIGHTS}

- The behaviour of ferritic stainless steel beam-columns is investigated.

- FE results considering different bending moment diagrams are presented.

- The assessment of design approaches for flexural buckling resistance is presented.

- Interaction expressions for combined loading in beam-columns are assessed.

\section{INTRODUCTION}

The use of stainless steel structural elements in construction has been increasingly spread in the last years as a result of its excellent corrosion resistance, easy maintenance, good mechanical properties and aesthetic appearance. Nevertheless, the utilization of these alloyed materials is still restrained by their needs of high initial investments. Ferritic stainless steels, with lower nickel content, are cheaper and more price-stable than the most usual austenitic grades, but still maintaining a significant corrosion resistance, good ductility, formability and impact resistance. Besides, as all stainless steel grades present a nonlinear stress-strain behaviour and a considerable strain hardening, the extension of EN1993-1-1 [1] specifications for carbon steel to stainless steels needs to be carefully developed and thus, EN1993-1-4 [2] statements are usually too conservative. Therefore, the development of specific and efficient guidance is key for the widespread usage of this material.

The behaviour of stainless steel columns has been briefly studied through experimental and numerical studies during the last decade, especially focused on the most usual austenitic grades. Thus, existing investigations regarding ferritic beam-columns is very limited, although some numerical analysis are available in very recent literature. Consequently, EN1993-1-4 [2] specifications for the consideration of the flexural buckling resistance of ferritic stainless steel columns still need to be studied, so as the interaction expressions for beam-columns. Some new approaches have been proposed for the consideration of the shape of the bending moment 
diagram and their applicability has been studied for different stainless steel grades and crosssectional types.

In order to complete this research, a comprehensive experimental programme on ferritic stainless steel RHS and SHS beam-columns will be conducted by the authors and this paper gathers the derived previous research works. Thus, the numerical studies concerning the buckling behaviour of ferritic stainless steel columns subjected to combined loading are presented, together with the assessment of the existing design approaches in order to investigate the efficiency of the coefficients used in such methods. Their reliability is hence strengthened and some modifications suitable to the ferritic stainless steel members will be eventually suggested to offer new ways apt to strike a balance between safety, conciseness of application and conservatism.

The process leading to the development of the current paper has involved different stages such as the study of the numerical modelling of structural ferritic stainless steel elements considering material and geometrical nonlinearities and imperfections, the study of the constitutive equations for ferritic stainless steels and the comparative analyses between the results derived from the numerical models and those obtained by using different design formulae.

\section{FLEXURAL BUCKLING}

A brief review of the different expressions available in the literature for the consideration of the flexural buckling of stainless steel beam-columns is presented in this section. Together with the expressions codified in EN1993-1-4 [2], some representative research works where this phenomenon is investigated are also described. 


\subsection{EN 1993-1-4 approach}

The expressions for the consideration of the flexural buckling behaviour of stainless steel columns currently codified in EN1993-1-4 [2] are presented herein, both for axial compression and for the interaction of axial compression and bending moment. Regarding the design of columns, the general method established in EN1993-1-1 [1] for carbon steel is considered also for stainless steel elements, where their different behaviour is accounted by defining different buckling curves and limiting slenderness than those codified for carbon steel. For cold-formed stainless steel hollow sections EN1993-1-4 [2] establishes the European buckling curve c, with the imperfection factor of $\alpha=0.49$ and the limiting slenderness of $\bar{\lambda}_{0}=0.4$. Hence, the ultimate capacity $\mathrm{N}_{\mathrm{b}, \mathrm{Rd}}$ is calculated from Eqs. (1)-(4) by considering $\beta=1$ for both axes of buckling.

$$
\begin{aligned}
& \mathrm{N}_{\mathrm{b}, \mathrm{Rd}}=\frac{\chi \mathrm{A} \sigma_{0.2}}{\gamma_{\mathrm{M} 1}} \\
& \chi=\frac{1}{\phi+\sqrt{\phi^{2}-\beta \bar{\lambda}^{2}}} \leq 1.0 \\
& \phi=0.5 \cdot\left[1+\alpha\left(\bar{\lambda}-\bar{\lambda}_{0}\right)+\beta \bar{\lambda}^{2}\right] \\
& \bar{\lambda}=\sqrt{\frac{\mathrm{A \sigma _{0.2 }}}{\mathrm{N}_{\mathrm{cr}}}}
\end{aligned}
$$

where $\mathrm{A}$ is the cross-sectional area (for Class 4 slender sections, the effective area is used), $\sigma_{0.2}$ is the $0.2 \%$ proof stress, $N_{c r}$ is the Euler elastic critical load for flexural buckling and $\gamma_{\mathrm{M} 1}$ is the instability partial safety factor. Those elements subjected to combined uniaxial bending and compression should also satisfy, according to EN1993-1-4 [2], the interaction equation given by Eq. (5) for those members not influenced by lateral-torsional buckling, where $i$ refers to y or $\mathrm{z}$ axis and the interaction factor $k_{i}$ can be determined according to Eq. (6). 


$$
\begin{aligned}
& \frac{\mathrm{N}_{\mathrm{Ed}}}{\mathrm{N}_{\mathrm{b}, \mathrm{i}, \mathrm{Rd}}}+\mathrm{k}_{\mathrm{i}}\left(\frac{\mathrm{M}_{\mathrm{i}, \mathrm{Ed}}+\mathrm{N}_{\mathrm{Ed}} \mathrm{e}_{\mathrm{Ni}}}{\beta_{\mathrm{W}} \mathrm{W}_{\mathrm{pl}, \mathrm{i}} \sigma_{0.2} / \gamma_{\mathrm{M} 1}}\right) \leq 1.0 \\
& \mathrm{k}_{\mathrm{i}}=1.0+2\left(\bar{\lambda}_{\mathrm{i}}-0.5\right) \frac{\mathrm{N}_{\mathrm{Ed}}}{\mathrm{N}_{\mathrm{b}, \mathrm{i}, \mathrm{Rd}}} \text { with } 1.2 \leq \mathrm{k}_{\mathrm{i}} \leq 1.2+2 \frac{\mathrm{N}_{\mathrm{Ed}}}{\mathrm{N}_{\mathrm{b}, \mathrm{i}, \mathrm{Rd}}}
\end{aligned}
$$

where $\mathrm{N}_{\mathrm{Ed}}$ and $\mathrm{M}_{\mathrm{i}, \mathrm{Ed}}$ are the design values of the compression force and the maximum moments respectively, $\beta_{\mathrm{W}}=1$ for Class 1 or 2 cross-sections, $\beta_{\mathrm{W}}=\mathrm{W}_{\mathrm{el}} / \mathrm{W}_{\mathrm{pl}}$ for Class 3 cross-sections and $\beta_{\mathrm{W}}=\mathrm{W}_{\mathrm{eff}} / \mathrm{W}_{\mathrm{pl}}$ for Class 4 cross-sections. $\mathrm{W}_{\mathrm{el}}$ and $\mathrm{W}_{\mathrm{pl}}$ are the elastic and plastic modulus and $\mathrm{e}_{\mathrm{Ni}}$ is the shift in the neutral axis when cross-section is subjected to uniform compression for Class 4 cross-sections.

\subsection{Alternative design approaches}

The literature used throughout the development of this paper regards some numerical-analytical works reported by international research groups for the determination of the flexural buckling capacity of stainless steel columns and the evaluation of elements subjected to bending and axial compression.

Lopes et al. [3] conducted a numerical study on austenitic stainless steel I columns subjected to compression, where the expression given in EN1993-1-4 [2] was evaluated and a new proposal was made by slightly modifying it in order to ensure conservative results, presented in Eq. (1)(4), but considering $\beta=1.5$. Lopes et al. [4] followed with the analysis extending it to I beamcolumns considering different stainless steel grades and bending moment diagrams. The two methods proposed in EN1993-1-1 [1] for carbon steel were considered, in addition to the expressions codified in EN1993-1-4 [2], and a new equation considering the shape of the bending diagram was proposed for the evaluation of stainless steel columns. This new proposal is described by Eq. (7)-(10). 


$$
\begin{aligned}
& \mathrm{k}_{\mathrm{i}}=1-\frac{\mu_{\mathrm{i}} \mathrm{N}_{\mathrm{Ed}}}{\mathrm{N}_{\mathrm{b}, \mathrm{Rd}, \mathrm{i}}} \text { but } \mathrm{k}_{\mathrm{i}} \leq 1.5 \text { and } \mathrm{k}_{\mathrm{i}} \geq \mu_{\mathrm{i}}-0.7 \\
& \mu_{\mathrm{y}}=\left(0.97 \beta_{\mathrm{M}, \mathrm{y}}-2.11\right) \bar{\lambda}_{\mathrm{y}}+0.44 \beta_{\mathrm{M}, \mathrm{y}}+0.09 \text { if } \bar{\lambda}_{\mathrm{y}} \leq 0.3 \text { then } \mu_{\mathrm{y}} \leq 1.0 \text { else } \mu_{\mathrm{y}} \leq 0.9 \\
& \mu_{\mathrm{z}}=\left(1.09 \beta_{\mathrm{M}, \mathrm{z}}-2.32\right) \bar{\lambda}_{\mathrm{y}}+0.29 \beta_{\mathrm{M}, \mathrm{y}}+0.48 \text { if } \bar{\lambda}_{\mathrm{y}} \leq 0.3 \text { then } \mu_{\mathrm{y}} \leq 1.0 \text { else } \mu_{\mathrm{y}} \leq 0.9 \\
& \beta_{\mathrm{M}, \mathrm{i}}=1.8-0.7 \psi
\end{aligned}
$$

A recent research by Jandera and Syamsuddin [5] extended this study to rectangular and square hollow sections (RHS and SHS) and I stainless steel columns, also considering different bending moment diagrams and stainless steel grades. The proposal for I sections published by Lopes et al. [4] was found to be unsafe for the analysed cases, but with a low scatter, and a small modification of the expression was proposed: multiplying the expression given in Eq. (7) by 1.2 and omitting the upper and lower bounds. However, the proposal was limited to axial force and strong-weak axes bending of members which were not influenced by lateral-torsional buckling.

Greiner and Kettler [6] also investigated the behaviour of austenitic and duplex stainless steel I, rectangular hollow section (RHS) and circular hollow section (CHS) elements subjected to combined axial compression and uniform bending diagrams through a numerical study. It was concluded that the interaction behaviour of stainless steel members under combined loading can be well represented by interaction formulae of the same structure as for carbon steel, although specific buckling coefficients and interaction factors need to be considered. Additionally, a new interaction expression for the interaction factor $k_{i}$ given by Eqs. (11)-(12) was proposed for cold-formed RHS.

$$
\begin{aligned}
& \mathrm{k}_{\mathrm{i}}=0.9+3.5\left(\overline{\mathrm{n}}_{\mathrm{i}}\right)^{1.8}\left(\bar{\lambda}_{\mathrm{i}}-0.5\right) \leq 0.9+1.75\left(\overline{\mathrm{n}}_{\mathrm{i}}\right)^{1.8} \\
& \overline{\mathrm{n}}_{\mathrm{i}}=\frac{\mathrm{N}_{\mathrm{Ed}}}{\chi \mathrm{A} \sigma_{0.2}}
\end{aligned}
$$


Hradil and Talja [7] investigated the influence of different material parameters of the constitutive equation for stainless steels defined in EN1993-1-4 [2] on the ultimate buckling resistance of RHS columns. The consideration of the effect of the material nonlinearity was proposed by a new method based on the Ayrton-Perry model. The evaluation of the different buckling curves was later conducted by an extensive numerical analysis in Hradil et al. [8], where it was concluded that for cold-rolled sections, the effect of the considered material properties (virgin material strength, flat part strength or average strength) strongly affects the applicability and suitability of the current buckling curves.

Partial resistance factors for the design of stainless steel elements were re-evaluated by Francis and Baddoo [9] after collecting and analysing a large body of laboratory test data on stainless steel structural members. These experimental data were statistically analysed according to Annex D of EN1990 [10] and compared to the ones currently codified in EN1993-1-4 [2]. The analysis showed that a potential problem exists with RHS members in compression. For austenitic stainless steel a reasonable partial resistance factor was achieved $\left(\gamma_{\mathrm{M} 1}=1.1\right)$, but for duplex and ferritic stainless steels $\gamma_{\mathrm{M} 1}=1.2$ would appear to be more appropriate. Given the number of test data available, this could also be an indication that the buckling curve is too high. Hence, further interpretation of the results and discussion is needed.

Thus, this present investigation intends to confirm the different methods presented herein and to extend them to ferritic stainless steel hollow sections subjected to non-uniform distribution of bending moment through a comprehensive numerical study.

\section{NUMERICAL INVESTIGATION}

The model employed throughout the present investigation was based on finite element method (FE) since it has been extensively demonstrated that it can be considered a method able to give the efficiency, accuracy and versatility necessary to solve nonlinear problems in engineering. 
This section includes the presentation of the general basis of numerical model made to simulate the structural behaviour of stainless steel columns. Both geometrical and material nonlinearities were considered in the models generated by the general purpose FE software Abaqus.

\subsection{General considerations}

RHS and SHS columns with different geometries have been analysed in this work. Regarding boundary conditions and loads, a scheme of pin-ended beam subjected to combined loading at the top end was developed, introducing the loads as imposed displacements. At both ends the rotational degree of freedom around the axis of buckling was not restrained as well as the vertical translational degree at the loaded end.

Due to the thin-walled nature of the examined sections, shell elements were employed with the aim to discretize the models, as they are able to support both membrane (where axial forces appear in the mid-surface of the element) and bending actions (typically developed in plates) consistent with classical shell theory. The effectiveness of this choice was confirmed by previous studies and investigations [11]-[15]. Therefore, the finite element used is S4R, or rather, a 4-noded doubly curved shell element with reduced integration.

Since the constitutive models are mathematical equations that, together with equilibrium and compatibility equations, are absolutely essential to determine the relations between stresses, strains and displacements in a structure, it is necessary to evaluate them accurately. Thus, it is important to analyse the features of the materials in order to choose the constitutive model which better reproduces the real behaviour of the material which is purpose of the analysis. When no measured experimental stress-strain curves were accessible, the behaviour of stainless steel was modelled using the material model proposed by Mirambell and Real [16] and the expressions reported in Arrayago et al. [17] for the determination of the different material parameters from the three basic parameters reported. The enhancement of the mechanic 
characteristics along the section due to the hardening of the material during the deformation and the operation of cold-forming was also considered in the FE models, where the region affected by the enhancement was considered to involve also a zone belonging to the flat parts adjacent to the curved portions of the corners and equal two times the thickness of the section, $[13,15]$

\subsection{Model validation}

The adequacy of the developed model to reproduce the response of actual stainless steel columns is checked in this section. The first step in the validation process was to develop a convergence study in order to investigate the behaviour of the model in terms of accuracy and computational cost, by increasing the mesh density. The second step was to compare the experimental results of a stainless steel column subjected to a compressive axial load with the numerical results derived from the corresponding FE model. Experimental results on austenitic stainless steel columns published by Theofanous and Gardner [18] and those on ferritic columns conducted by Afshan and Gardner [19] were considered in the comparison. All the measured geometric properties and key material parameters are reported in the original publications, and were used to develop the FE models.

The shape of the initial global geometric imperfection was derived from a linear eigenvalue buckling analysis, while the following imperfection amplitudes $\mathrm{e}_{0}$ were adopted in the study in order to see how the analysis was influenced by the initial global imperfection: L/500, L/1000, $\mathrm{L} / 1500$ and $\mathrm{L} / 2000$, where $\mathrm{L}$ is the total length of the column.

The comparisons between the experimental and FE results in terms of load-lateral deflection curves are presented in Figure 1 for a SHS column and a RHS column considering both major (Mj) and minor (Mi) axes column from [18] and a SHS column from [19]. All the considered columns were tested under pin-ended conditions and the total length of the specimens was 
$1200 \mathrm{~mm}$ for $80 \mathrm{x} 40 \mathrm{x} 4-\mathrm{Mj}$ and $80 \mathrm{x} 40 \mathrm{x} 4-\mathrm{Mi}$ columns, 2000mm for $60 \mathrm{x} 60 \mathrm{x} 3$ and $1577 \mathrm{~mm}$ for 80x80x3. Table 1 also presents the numerical-to-experimental ultimate load ratios and the corresponding lateral deflection ratios for each considered initial global imperfection amplitude. It is worth mentioning that the best results are obtained using the imperfection amplitude L/1500, which coincides with the total imperfection amplitude measured in the tested specimens, as reported in [18] and [19].

Table 1. Comparison between experimental and FE results for stainless steel columns subjected to flexural buckling.

Figure 1. Comparison between FE models and experimental results for RHS and SHS subjected to flexural buckling for L/1500 imperfection amplitude [18] and [19]

For the specimens considered from the experimental programme described in [18], numerical results obtained herein have also been compared to those FE curves published in the original paper, and are plotted in Figure 2. FE models from both analyses compared in this figure consider an initial global imperfection amplitude of L/1500, which was that observed during the tests.

Figure 2. Comparison between reported and conducted FE models for RHS and SHS subjected to flexural buckling for L/1500 imperfection amplitude, [18]

Figures 1-2 and Table 1 demonstrate that the results derived from the numerical model are in good agreement with the experimental and numerical results presented by [18] and [19].

\section{FERRITIC STAINLESS STEEL COLUMNS SUBJECTED TO COMBINED LOADING}

\subsection{Introduction}

In order to better understand the response of stainless steel columns subjected to combined loading, some experimental tests will be carried out at the Laboratori de Tecnologia d'Estructures Lluís Agulló, at Universitat Politècnica de Catalunya (UPC), which will 
contribute to the study of the interaction between axial compression and bending moment in ferritic stainless steel RHS and SHS columns. Before conducting the experimental programme, an exhaustive numerical analysis was conducted in order to identify the key aspects of the phenomena and provide an adequate test planning. The FE study consisted of the cross-sections and element lengths to be tested, although several additional loading cases were also included, with different load eccentricities and bending moment distributions: constant, triangular and bitriangular distributions, $\Psi=1, \Psi=0$ and $\Psi=-1$ respectively, where $\Psi$ is the end bending moment ratio. Three cross-sections were analysed: $80 \times 80 \times 4,80 \times 40 \times 4$ and 70x50x2. For each bending distribution, different eccentricities were considered, ranging between $0-500 \mathrm{~mm}$ and providing several axial compression-to-bending moment ratios. Thus, a database of more than 170 numerical results was considered.

For RHS, buckling around minor and major axes was considered; in the first situation the column was left free to buckle around the minor axis, while in the second case, the rotation around it was restrained in order to force the column to bend around the major axis. In any case, the ultimate axial load $\mathrm{N}_{\mathrm{u}}$ resulting from the numerical analysis was multiplied by the corresponding imposed eccentricity in order to obtain the corresponding ultimate bending moment $\mathrm{M}_{\mathrm{u}}$. Concerning load eccentricity, it was always placed in the plane of the initial global imperfection in such a way to increase the displacement in that plane. The stability problem was analysed in two steps: an initial eigenvalue analysis for the determination of the shape of the initial imperfection and a second GMNIA analysis including material and geometrical nonlinearities to study the behaviour of the structure once the buckling has taken place, or rather the post-critical behaviour.

The geometric and material properties of the studied specimens are presented in the following section, together with some considerations regarding the determination of the initial imperfection amplitude. 


\subsection{Geometry and material definition}

Three different cross-sections, including one SHS 80x80x4 and two RHS columns, 80x40x4 and $70 \times 50 x 2$, with a nominal length of $1500 \mathrm{~mm}$ were considered in the study. Table 2 presents the average measured key geometrical parameters, where $\mathrm{L}$ is the total length of the specimens, $\mathrm{H}$ is the total height, $\mathrm{B}$ is the total width, $\mathrm{t}$ is the thickness and $\mathrm{R}_{\mathrm{ext}}$ is the external corner radius. The definition of the geometrical parameters is presented in Figure 3.

Table 2. Average measured dimensions.

Cold-forming processes have a great effect on the behaviour of the cross-sections as the plastic deformations endured, especially in the corner parts, cause material property enhancement. Hence, the material behaviour of the different cross-sections was characterized by conducting some tensile tests on coupons extracted both from the flat $(\mathrm{F})$ and corner $(\mathrm{C})$ parts of the crosssections, as presented in Figure 3.

Figure 3. Location of flat and corner coupons and definition of cross section symbols. Two flat specimens and two corner coupons were tested in the technical laboratories of Acerinox for each analysed cross-section according to the specifications gathered in ISO 68921 [20]. Average key material properties of the flat and corner regions of each cross-section are shown in Table 3, where $\mathrm{E}$ is the Young's modulus, $\sigma_{0.05}$ and $\sigma_{0.2}$ are the proof stresses corresponding to $0.05 \%$ and $0.2 \%$ plastic strains respectively, $\sigma_{\mathrm{u}}$ is the ultimate tensile stress, $\varepsilon_{\mathrm{u}}$ is the corresponding ultimate strain, $\varepsilon_{\mathrm{f}}$ is the strain at fracture and $\mathrm{n}$ and $\mathrm{m}$ are the strainhardening parameters corresponding to the material model proposed by Mirambell and Real [16]. These values have been obtained from the actual stress-strain curves measured during the tensile tests through a software developed by the authors and described in Real et al. [21] and Arrayago et al. [17] that permits to obtain the values of these key material properties. Young's modulus values reported in Table 3 for corner coupons are significantly lower than for flat specimens and those expected for this ferritic stainless steel grade. This is probably due to the 
complex geometry of the corner coupons and the difficulties associated with the gripping process in the test machine, which might have introduced unexpected bending effects and reduced the apparent Young's modulus.

Additionally, the experimental ultimate strain values have been compared with those calculated from the expression codified in EN 1993-1-4, Annex C [2], which are found to be too optimistic for the analysed cold-formed ferritic coupons. However, this expression was based on austenitic and duplex stainless steel grades, which exhibit more ductile behaviour than ferritics do.

Table 3. Average tensile test results for flat (F) and corner (C) parts. The different behaviour of flat and corner parts of cross-sections can be easily considered in the analysis of the results by determining the weighted average material properties as established in [7]. The value of the material parameter to be calculated is assigned to the relevant part of the cross-section and weighted according to the area referred to the total area of the cross-section. The weighted average material properties of the different cross-sections presented in this paper are summarized in Table 4, together with the nominal material properties established in EN1993-1-4 [2] for the ferritic grade EN1.4003. However, and due to the bending effect present in the corner specimens when testing, only Young's modulus values corresponding only to flat coupons have been considered.

Table 4. Weighted tensile material properties.

Membrane residual stresses were found to be relatively insignificant in stainless steel hollow sections by Cruise and Gardner [22] and bending residual stresses are considered to be inherently present in the material properties when measured stress-strain curves are considered in FE models. Therefore, no residual stresses have been explicitly introduced into the models. 


\subsection{Cross-sectional classification}

European Standard EN1993-1-4 [2] for the design of structural stainless steel elements accounts for the effect of local buckling through the cross-section classification concept given in EN1993-1-1 [1], where for each cross-section, the part subjected to compression and the part subjected to bending and compression need to be identified. During the design approach it is simple to evaluate the class of each part belonging to the whole cross-section simply using the design axial compression load $\mathrm{N}_{\mathrm{Ed}}$ in order to define the part of the element subjected to compression, which is generally accounted through the $\alpha$ parameter.

The assignment of a certain class indicative of its sensitivity to local buckling is conducted by comparing certain limits with the c/ct slenderness of the most slender constituent plate element, considering both key geometrical and material properties of the studied element, where $\mathrm{c}$ is the width or depth of a part of a cross-section, $\mathrm{t}$ is the element thickness and $\varepsilon$ considers material properties, defined as $\varepsilon=\left[\left(235 / \sigma_{0.2}\right) \cdot(\mathrm{E} / 210000)\right]^{0.5}$, and $\mathrm{E}$ is the Young's modulus. The different class limits depend on this $\alpha$ parameter that accounts for the compressed part of the cross-section, and usually estimated from the design axial compression load $\mathrm{N}_{\mathrm{Ed}}$. When predicting the ultimate capacity of a cross-section, this axial compression load is unknown, and the $\alpha$ parameter cannot be calculated.

Thus, it was decided to evaluate separately the class of each cross-section under compression and under bending moment, in order to obtain the values of the corresponding area A and the section modulus $\mathrm{W}$, respectively. Therefore, the gross area was assigned to those cross-sections classified as Class 1, 2 or 3, the effective area to Class 4 cross-sections, and in bending, the plastic section modulus $\mathrm{W}_{\mathrm{pl}}$ was assigned to the elements which resulted to be in Class 1 and 2, meanwhile, for Class 3 cross-sections, the elastic section modulus $\mathrm{W}_{\mathrm{el}}$ was adopted. Finally, for Class 4 cross-sections the effective section modulus $\mathrm{W}_{\text {eff }}$ was evaluated. 
An important issue that should be considered is the value of the Young's modulus E and the $0.2 \%$ proof stress $\sigma_{0.2}$ used in the evaluation of the $\varepsilon$ parameter, as those values obtained from considering virgin material, flat parts or weighted average properties can be considered. E and $\sigma_{0.2}$ values considered herein are weighted over the corresponding limiting flat part, as given in Eqs. (13)-(14), in a similar manner to the treatment of the entire cross-section presented in the previous section, but only referred to the flat parts. These flat parts are considered to be composed by the flat material in the central parts and by the hardened steel in the two segments adjacent to the curved portions at the corners, each one of width equal to $2 t$, where $t$ is the thickness of the section. Similar assumptions were adopted in $[13,15,18]$.

$$
\begin{aligned}
E_{\text {class }} & =\frac{E_{\text {flat }}\left(H-2 R_{\text {ext }}-4 t\right) t+E_{\text {corner }} 4 t^{2}}{\left(H-2 R_{\text {ext }}\right) t} \\
\sigma_{0.2 \text {, class }} & =\frac{\sigma_{0.2 \text {,flat }}\left(H-2 R_{\text {ext }}-4 t\right) t+\sigma_{0.2, \text { corner }} 4 t^{2}}{\left(H-2 R_{\text {ext }}\right) t}
\end{aligned}
$$

\subsection{Determination of global initial imperfections}

The ultimate capacities of ferritic stainless steel RHS and SHS columns subjected to combined loading were obtained by conducting numerical nonlinear analyses, considering both material and geometrical nonlinearities. The determination of the shape of the global initial imperfections was derived from a linear eigenvalue buckling analysis, whereas the amplitude of these imperfections $\mathrm{e}_{0}$ needed to be carefully defined.

Since EN1993-1-4 [2] for stainless steels provides no specific methodology for the determination of the initial imperfection amplitude, the procedure gathered in EN1993-1-1 [1] for carbon steel elements and given by Eqs. (15)-(16) was considered by changing the limiting slenderness $\bar{\lambda}_{0}$. This parameter is defined as $\bar{\lambda}_{0}=0.2$ in EN1993-1-1 [1] but it was decided to change it when adapting these expressions to stainless steels by adopting $\bar{\lambda}_{0}=0.4$, which is the limiting slenderness considered in EN1993-1-4 [2] for the determination of the flexural 
buckling resistance of stainless steel cold-formed sections. The meaning of the different symbols has already been defined along the paper.

This approach was used in order to obtain the initial imperfection amplitude in absence of the measured ones and determine realistic values of the amplitudes. In case of simply supported beams $\mathrm{e}_{0}^{\prime}=\mathrm{e}_{0}$ coincide, because the ratio $\mathrm{N}_{\mathrm{cr}} / \mathrm{EI}_{\mathrm{cr}, \max }^{\prime \prime}$ is equal to $1 /[\mathrm{m}]$. The calculation of the characteristic axial $\mathrm{N}_{\mathrm{Rk}}$ and bending moment resistances $\mathrm{M}_{\mathrm{Rk}}$ of the critical cross-section was derived by taking into account the cross-sectional classification considerations described in the previous section.

$\mathrm{e}_{0}^{\prime}=\mathrm{e}_{0} \frac{\mathrm{N}_{\mathrm{cr}}}{\mathrm{EI}_{\mathrm{cr}, \max }^{\prime \prime}}$

$\mathrm{e}_{0}=\alpha\left(\bar{\lambda}-\bar{\lambda}_{0}\right) \frac{\mathrm{M}_{\mathrm{Rk}}}{\mathrm{N}_{\mathrm{Rk}}} \frac{1-\frac{\chi \bar{\lambda}^{2}}{\gamma_{\mathrm{M} 1}}}{1-\chi \bar{\lambda}^{2}}$

\section{RESULTS AND DESIGN APPROACH ASSESSMENT}

The assessment of the different design approaches codified in EN1993-1-4 [2] and proposed in the literature is presented in this section through a comparison of the predicted ultimate capacities with those obtained from FE analysis. First, the flexural buckling resistance is assessed, followed by the analysis of the interaction expressions for combined compression and bending moment load situations, where the different methods are assessed and the interaction coefficient $k$ is studied.

\subsection{Assessment of flexural buckling resistance $\mathbf{N}_{b, R d}$}

FE results for RHS and SHS columns subjected to compression and their comparison with the different approaches are illustrated in this section, where the expression codified in EN1993-14 [2], described by Eqs. (1)-(4) with $\beta=1$ and the one proposed by Lopes et al. [3] for austenitic stainless steel I columns, with $\beta=1.5$, are analysed. For RHS, the flexural buckling behaviour 
regarding major $(\mathrm{Mj})$ and minor $(\mathrm{Mi})$ axes has been analysed. The assessment of both approaches is presented in Table 5, where the predicted-to-numerical ultimate load ratios are gathered, together with the mean values and the coefficients of variation (COV.). The partial safety factor $\gamma_{\mathrm{M} 1}$, which is partly related to the dispersions resulting from the material and geometrical properties, equal to unity and the one codified in EN1993-1-4 [2] have been considered. Regarding material properties, the experimental ones presented in section 4.2 and those provided in EN1993-1-4 [2], named nominal, have been adopted. The experimental and nominal values of the key parameters for the ferritic grade EN1.4003 are presented in Table 4. The most relevant situations are those where the nominal material properties are considered together with a partial safety factor $\gamma_{M 1}=1.1$, which is the value a designer would get, and those where the experimental material properties are combined with a partial safety factor $\gamma_{\mathrm{M} 1}=1.0$ for evaluating the design expressions themselves. However, the four situations have been considered for comparison.

Table 5. Assessment of flexural buckling resistance of ferritic stainless steel columns for different approaches, $\gamma_{\mathrm{M} 1}$ values and material properties.

Table 5 demonstrates that, as previously highlighted by other authors $[3,23]$, the method for the determination of the ultimate flexural buckling capacity of ferritic RHS elements currently codified in EN1993-1-4 [2] overestimates the actual response of some of the columns (80x40x4), even when $\gamma_{M 1}=1.1$ is considered. It can be additionally highlighted that the adoption of nominal material properties coded in EN1993-1-4 [2] also provides unsafe predictions of the ultimate capacities of some of the considered elements, such as $80 x 40 \times 4-\mathrm{Mi}$. Regarding the new proposal suggested by [3], the predictions of the ultimate capacities are more accurate (as the $\beta=1.5$ parameter shifts down the considered buckling curve) and most of them remain on the safe side. The considerable differences between considering the nominal or experimental material properties are mainly caused by the different $\sigma_{0.2}$ values considered: 
$\sigma_{0.2}=280 \mathrm{MPa}$ for nominal material properties, whereas $\sigma_{0.2}$ values between $500-580 \mathrm{MPa}$ are adopted when experimental properties are used, which also influences on the determination of the relative slenderness $\bar{\lambda}$.

Some uncertainties about the value of the partial safety factor $\gamma_{M 1}$ are therefore appreciated in Table 5 as the specifications coded in EN1993-1-4 [2] approach seem to be non-conservative for few cross-sections, regardless the considered material properties, as established by Francis and Baddoo [9] before. Thus, the possibility of recommending a higher factor should be considered after conducting more extensive experimental and numerical investigations in order to provide an acceptably low probability of failure.

\subsection{Assessment of the approaches for combined loading}

The main objective of the research work presented in this paper is, as highlighted before, to conduct a comprehensive preliminary numerical analysis on ferritic RHS and SHS elements subjected to combined axial compression and bending moment in order to assess the applicability of the existing design approaches. Besides different cross-sections, several bending-moment distributions have been considered (constant, triangular and bi-triangular distributions, $\Psi=1, \Psi=0$ and $\Psi=-1$ respectively), including different load eccentricities. FE results have been therefore compared to those calculated by the different approaches presented in section 2 in order to evaluate them as capable of representing the flexural buckling behaviour of these elements.

\subsubsection{Discussion and assessment of EN1993-1-4 approach}

The interaction expression codified in EN1993-1-4 [2] has been evaluated, as in previous section, attending to two different material property definitions, nominal and experimental values gathered in Table 4 . Considering that the ultimate capacity values calculated by 
designers will be those obtained from adopting nominal material properties and $\gamma_{\mathrm{M} 1}=1.1$, it is of great interest to evaluate the adequacy of this situation. Additionally, the interaction expressions assuming experimental material properties, but assuming $\gamma_{\mathrm{M} 1}=1.0$, have also been considered for comparison, as mentioned in previous section. Figures 4(a) and 4(b) present the obtained ultimate compression-bending moment responses for different bending moment distributions for cross-sections $80 \times 80 \times 4$ and 80x40x4-Mi respectively, as representative of the studied cases. In order to facilitate the comparison of the analysed cross-sections, both axial compression and bending moment have been normalized against the plastic resistance $\mathrm{N}_{\mathrm{pl}}$ and the plastic bending moment capacity $\mathrm{M}_{\mathrm{p}}$, respectively. As these figures demonstrate, the adoption of nominal material properties and $\gamma_{\mathrm{M} 1}=1.1$ usually derives into conservative ultimate load predictions, although some unsafe results can be observed. This indicates, as previously mentioned, that $\gamma_{\mathrm{M} 1}$ values should be carefully revised.

Figure 4. Assessment of the interaction expressions coded in EN1993-1-4 [2] for different material properties and $\gamma_{\mathrm{M} 1}$ values.

For assessing the design provisions, proportional loading was assumed and the ratio by which each FE data point exceeded or fell short of its respective design interaction curve was calculated and denoted $U$. Note that a value of $U$ greater than unity indicates an unsafe prediction of the ultimate capacity. These ratios have been calculated according to Eq. (17) and the graphical definition is also presented in Figure 5.

$\mathrm{U}=\mathrm{R}_{\text {pred }} / \mathrm{R}_{\mathrm{FE}}$

Figure 5. Graphic definition of U parameter for the assessment of design approaches.

Table 6 gathers the assessment of the interaction expression codified in EN1993-1-4 [2] through the $\mathrm{U}$ parameters for the consideration of both nominal material properties with 
$\gamma_{\mathrm{M} 1}=1.1$ and experimental properties with $\gamma_{\mathrm{M} 1}=1.0$. The results for all cross-sections and different bending moment diagram shapes are presented for comparison. Figure 6 also presents the assessment of both hypotheses, where $\mathrm{R}_{\mathrm{FE}}$ values are compared against $\mathrm{R}_{\text {pred. }}$. For this assessment, the actual cross-sectional classification has been derived once the values of the ultimate axial compression and bending moment were determined in FE analysis. It was observed that the classification of a few elements subjected to combined loading changed comparing with that obtained assuming pure bending, as considered in Section 4.3.

Table 6. Assessment of EN1993-1-4 design approach considering different material properties for ferritic RHS and SHS beam-columns.

Concerning Table 6, it can be highlighted that given the fact that Eqs. (5)-(6) do not consider the shape of the bending moment diagram, results get more overconservative as the shape of this diagram differs from the constant one $(\Psi=1)$, providing higher $U$ values. Since nominal $\sigma_{0.2}$ values are considerably lower than experimental ones, the accuracy of the calculated ultimate loads for experimental material properties is higher. Figure 6 demonstrates that the adoption of the interaction expression codified in EN1993-1-4 [2] usually provides safe and conservative results, being overconservative when nominal material parameters are considered. However, some unsafe predictions, especially when experimental properties are assumed, need to be carefully studied.

Figure 6. Assessment of the interaction expressions coded in EN1993-1-4 [2] for different material properties and $\gamma_{\mathrm{M} 1}$ values.

\subsubsection{Discussion and assessment of alternative design approaches}

The different approaches available in the literature for the consideration of the combined axial compression and bending moment and presented in section 2 have been assessed in order to identify the most appropriate one for ferritic RHS and SHS elements. Interaction expressions proposed by Lopes et al. [4], Jandera and Syamsuddin [5] and Greiner and Kettler [6] have 
been assessed by comparing the predicted and numerical ultimate loads. The different interaction expressions, and specially, the $k$ interaction factors, were proposed considering the ultimate flexural buckling and bending moment resistances calculated from FE analysis, so they usually describe just the shape of the interaction curves between the end-points of the pure axial compression and pure bending moment resistances, without influencing the end-points themselves. Therefore, the numerical flexural buckling and bending moment resistances have been adopted in this section, together with the partial safety factor equal to 1.0 , for the assessment of these interaction expressions. Note that the correct combined section capacity can only be correctly predicted when the flexural buckling and bending resistances are accurate and therefore, calculating these resistances according to EN1993-1-4 [2] specifications considering cross-sectional classification would lead into different results.

It is also important to note that the interaction expression proposed by Lopes et al. [4] was derived for I sections, where the behaviour relative to both principal axes needs to be considered separately. However, when this approach is evaluated for the RHS and SHS crosssections analysed herein, no distinction between $y-y$ and $z-z$ axis has been considered, using Eq. (8) for both major and minor axis. Figures 7-9 present the obtained non-dimensional numerical results for 80x80x4 and 80x40x4-Mi together with the different approaches. For comparison, the interaction expression codified in EN1993-1-4 [2] has also been included, where the ultimate capacities according to FE analysis have been adopted.

Figure 7. Assessment of [2] and [4] interaction approaches for 80x80x4 and 80x40x4-Mi. Figure 8. Assessment of [2] and [5] interaction approaches for 80x $80 \times 4$ and 80x40x4-Mi. Figure 9. Assessment of [2] and [6] interaction approaches for 80x80x4 and 80x40x4-Mi. Table 7 presents the assessment of the different studied design approaches, where average $U$ ratios calculated according to Eq. (17) and Figure 5 are presented for each interaction 
expression, cross-section and bending moment distribution. Nevertheless, as the calculation of average ratios sometimes conceal several unsafe predictions for some of the considered interaction expressions, all the results are also presented for EN1993-1-4 [2], Lopes et al. [4], Jandera and Syamsuddin [5] and Greiner and Kettler [6] in Figure 10.

Table 7. Assessment of different design approaches for ferritic RHS beam-columns.

Table 7, together with Figure 10(a) and (d), demonstrates that the interaction approach currently codified in EN1993-1-4 [2] and the one proposed by Greiner and Kettler [6] provide quite conservative results, especially regarding non-uniform bending moment distributions, as they do not consider the shape of the bending moment diagram. Nonetheless, some unsafe predictions of the ultimate capacity of ferritic stainless steel RHS and SHS columns subjected to combined loading can be found. Concerning the approach proposed by Lopes et al. [4] for austenitic I sections, it seems to be the one providing more accurate and less scattered results, but with several unsafe predictions. The modification proposed in Jandera and Syamsuddin [5], eliminates the majority these unsafe predictions, but results in a more conservative and scattered proposal.

Figure 10. Assessment of the interaction expressions in EN1993-1-4 [2] and proposed by Lopes et al. [4], Jandera and Syamsuddin [5] and Greiner and Kettler [6].

\subsubsection{Interaction factor $k$}

The analysis carried out in the previous section demonstrated that the most appropriate approach for the evaluation of the combined loading conditions on ferritic RHS and SHS beamcolumns is that proposed by Lopes et al. [4], as it is the method that provides quite accurate results with low scatter. As this proposal was derived from an analysis on austenitic stainless steel I sections, this paper intends to adjust this $k$ interaction factor to ferritic RHS elements in a similar way to what was presented by Jandera and Syamsuddin [5]. 
The method for this adjustment is slightly different from the one followed in Jandera and Syamsuddin [5], where a unique constant was used in the recalibration. The expression used in the adjustment in this work is $\mathrm{k}_{\mathrm{y}}=\mathrm{A}-\mathrm{B} \mu_{\mathrm{y}} \mathrm{N}_{\mathrm{Ed}} / \mathrm{N}_{\mathrm{b}, \mathrm{Rk}}$ where $\mathrm{A}$ and $\mathrm{B}$ are the constants to be determined. Nevertheless, and in order to not limiting the interaction factor to a minimum value so that the full bending capacity of the cross-section can be achieved in absence of axial compression, the A factor is set to unity. With the purpose of obtaining the best adjustment for $\mathrm{B}$, the numerical $k$ values have been calculated and compared to those obtained by using the new equation. The optimum expression has been determined by an Ordinary Least Squares Method (OLSM). In this expressions, the flexural buckling $\mathrm{N}_{\mathrm{b}, \mathrm{Rk}}$ and pure bending $\mathrm{M}_{\mathrm{c}, \mathrm{Rk}}$ resistances determined through $\mathrm{FE}$ analysis have been used and both major and minor axis buckling have been considered together. The adjustment of the available numerical data has provided Eq. (18) as the best approach for the interaction factor $k$. Note that this proposal is limited to axial force and uniaxial bending of members which are not influenced by lateraltorsional buckling.

$$
\mathrm{k}=1-0.92 \frac{\mu_{\mathrm{y}} \mathrm{N}_{\mathrm{Ed}}}{\mathrm{N}_{\mathrm{b}, \mathrm{Rd}, \mathrm{y}}}
$$

Figure 11 presents the predicted-to-numerical interaction factor ratios depicted against the numerical compression loads normalized by the FE flexural buckling resistances. Even though the formula gives a good concordance, it could lead to unsafe results, mainly related to the linear bending moment distribution of columns subjected to low bending. Conversely, the variation of the interaction factor is less important when the member is mainly compressed, and so when low bending moments are treated.

Figure 11. Assessment of Eq. (18) for different $\mathrm{N}_{\mathrm{FE}} / \mathrm{N}_{\mathrm{b}, \mathrm{Rk}}$ ratios. 
The assessment of this new expression for the interaction factor $k$ is presented in Figure 12 and Table 8, where it can be appreciated that a very good agreement is observed in terms of average values and low scatter, even if some unsafe results are also obtained. Thus, Eq. (18) should be more carefully studied with a higher database in order to get the best expression for the interaction factor.

Table 8. Assessment of the new proposal for ferritic RHS beam-columns.

Figure 12. Assessment of the new approach.

\section{CONCLUSIONS AND FUTURE RESEARCH WORKS}

A comprehensive numerical study on the behaviour of ferritic stainless steel RHS and SHS columns subjected to flexural buckling is presented in this paper. The expressions for the determination of the ultimate flexural buckling capacity currently available have been analysed and the different interaction approaches for combined axial compression and bending moment loading conditions have been also assessed. These numerical studies support an experimental programme that will be soon conducted in ferritic stainless steel RHS and SHS elements under combined loading.

The partial safety factor $\gamma_{\mathrm{M} 1}$ currently coded in EN1993-1-4 [2] has been found to provide unsafe ultimate flexural buckling resistance predictions, even when nominal material properties are considered, and the possibility of recommending a higher partial safety factor should be considered, as already established by Francis and Baddoo [9].

Regarding ferritic stainless steel RHS and SHS beam-columns, different bending and axial compression combinations for several bending moment diagram shapes have been considered for the evaluation of the design method codified in EN1993-1-4 [2] and those approaches available in the literature. Concerning EN1993-1-4 [2] approach, the adoption of nominal 
material properties and $\gamma_{\mathrm{M} 1}=1.1$ usually lead into overconservative ultimate load predictions, while the adoption of experimental material properties with $\gamma_{\mathrm{M} 1}=1.0$ is more accurate, although some unsafe results are obtained.

The analysis of the alternative design approaches highlighted that the consideration of the bending moment diagram shape into calculation is essential in order to correctly estimate the ultimate capacity of these elements, since the approaches proposed by Lopes et al. [4] and modified by Jandera and Syamsuddin [5] seem to be the most appropriate ones. Additionally, new coefficients for the $k$ interaction factor to ferritic RHS and SHS elements based on [4] has been proposed in this paper.

Conclusions extracted from this numerical study should be verified and more deeply analysed by the corresponding experimental tests, in which more cross-sections may also be included. The corresponding parametric study and statistical validation should be then conducted for the recommendation of a different $\gamma_{\mathrm{M} 1}$ factor and a new interaction factor proposal, in order to provide an acceptably low probability of failure.

\section{ACKNOWLEDGEMENTS}

This research was possible thank to the funding from the Ministerio de Economía y Competitividad (Spain) under the Project BIA 2012-36373. The first author would like to acknowledge the financial support provided by the Secretaria d'Universitats i de Recerca del Departament d'Economia i Coneixement de la Generalitat de Catalunya. The authors would also like to mention Acerinox for their special support and trust.

\section{REFERENCES}

[1] European Committee for Standardization. EN 1993-1-1. European Committee for Standardization Eurocode 3. Design of steel structures. Part 1-1: General rules and rules for buildings. Brussels, Belgium, 2005. 
[2] European Committee for Standardization Eurocode 3. Design of steel structures. Part 1-4:

General rules. Supplementary rules for stainless steels. Brussels, Belgium; 2006.

[3] Lopes N, Vila Real P and Simões da Silva L. Numerical modelling of the flexural buckling of axially loaded stainless steel members. Proceedings of the Third International Conference on Steel and Composite Structures ICSCS07, Manchester, United Kingdom, 2007.

[4] Lopes N, Vila Real P and Simões da Silva L. Stainless steel beam-columns interaction curves with and without lateral torsional buckling. 7th EUROMECH Solid Mechanics Conference, Lisbon, 2009.

[5] Jandera M and Syamsuddin D. Interaction formula for stainless steel beam-columns. Recent research advances on thin-walled structures, 2014. Proceedings of the Seventh European Conference on Steel and Composite Structures (EUROSTEEL), Napoli (Italy), 10-12 September 2014.

[6] Greiner R and Kettler M. Interaction of bending and axial compression of stainless steel members. Journal of Constructional Steel Research, 64(11):1217-1224, 2008.

[7] Hradil P and Talja A. Investigating the role of gradual yielding in stainless steel columns and beams by virtual testing. Proceedings of The Fifth International Conference on Structural Engineering, Mechanics and Computation. Cape Town, South Africa, 2013; 1459-1464.

[8] Hradil P, Fülöp L, and Talja A. Global stability of thin-walled ferritic stainless steel members. Recent research advances on thin-walled structures, 61:106-114, 2012.

[9] Francis P and Baddoo N. Re-evaluation of EN1993-1-4 partial resistance factors for stainless steel. Technical Report, SCI, 2013. 
[10] European Committee for Standardization. EN 1990. European Committee for

Standardization Eurocode. Basis of structural design. Brussels, Belgium, 2005.

[11] Gardner L and Nethercot D. Experiments on stainless steel hollow sections - Part 1:

Material and cross-sectional behaviour. Journal of Constructional Steel Research, (60): 12911318, 2004.

[12] Theofanous M, Gardner L and Chan T. Structural response of stainless steel oval hollow section compression members. Engineering Structures, 31(4): 922-934, 2009.

[13] Gardner L and Nethercot D. Numerical modelling of stainless steel structural componentsa consistent approach. Journal of Structural Engineering, 130(10): 1586-1601, 2004.

[14] Gardner L, Talja A and Baddoo N. Structural design of high-strength austenitic stainless steel. Thin-Walled Structures, 44(5):517-528, 2006.

[15] Ashraf M, Gardner L, and Nethercot D. Finite element modelling of structural stainless steel cross-sections. Thin-Walled Structures, 44(10):1048-1062, 2006.

[16] Mirambell E and Real E. On the calculation of deflections in structural stainless steel beams: an experimental and numerical investigation. Journal of Constructional Steel Research, 54(1): 109-133, 2000.

[17] Arrayago I, Real E and Gardner L. Material modelling of stainless steel alloys. (submitted to Materials \& Design)

[18] Theofanous M and Gardner L. Testing and numerical modelling of lean duplex stainless steel hollow section columns. Engineering Structures 31, 3047-3058, 2009. 
[19] Afshan S and Gardner L. Experimental study of cold-formed ferritic stainless steel hollow sections. Journal of Structural Engineering, 139 (special issue), 717-728. 2013.

[20] EN ISO 6892-1. Metallic materials - tensile testing - Part 1: method of test at room temperature. Brussels: European committee for standardization (CEN). 2009.

[21] Real E, Arrayago I, Mirambell E and Westeel R. Comparative study of analytical expressions for the modelling of stainless steel behaviour. Thin-Walled Structures 83, 2-11, 2012.

[22] Cruise RB and Gardner L. Residual stress analysis of structural stainless steel sections. Journal of Constructional Steel Research. 64(3); 352_66, 2008.

[23] Hradil P and Talja A. Numerical verification of stainless steel overall buckling curves. Thin-Walled Structures 83, 52-58, 2012. 


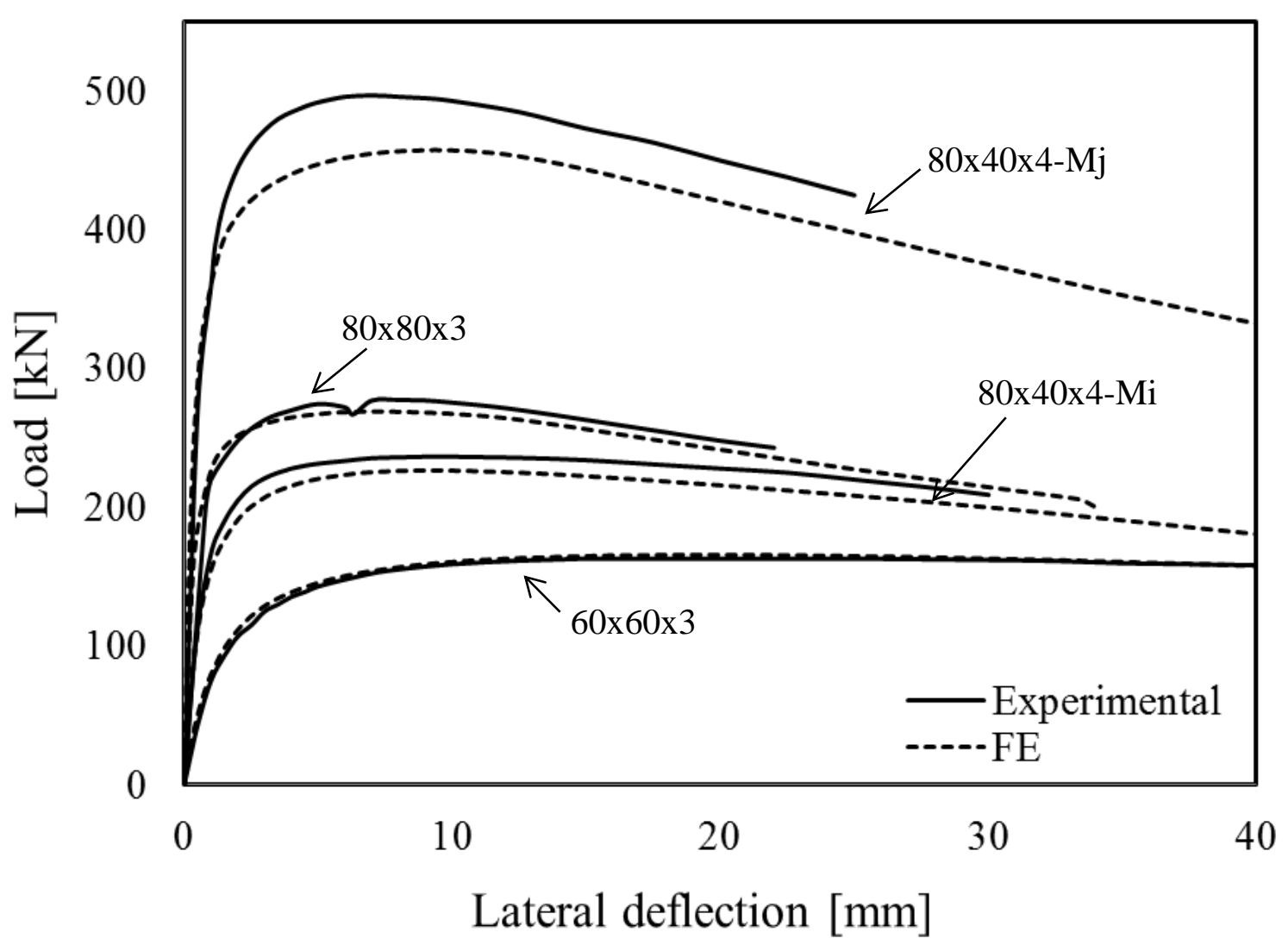

Figure 1. Comparison between FE models and experimental results for RHS and SHS subjected to flexural buckling for L/1500 imperfection amplitude [18] and [19] 


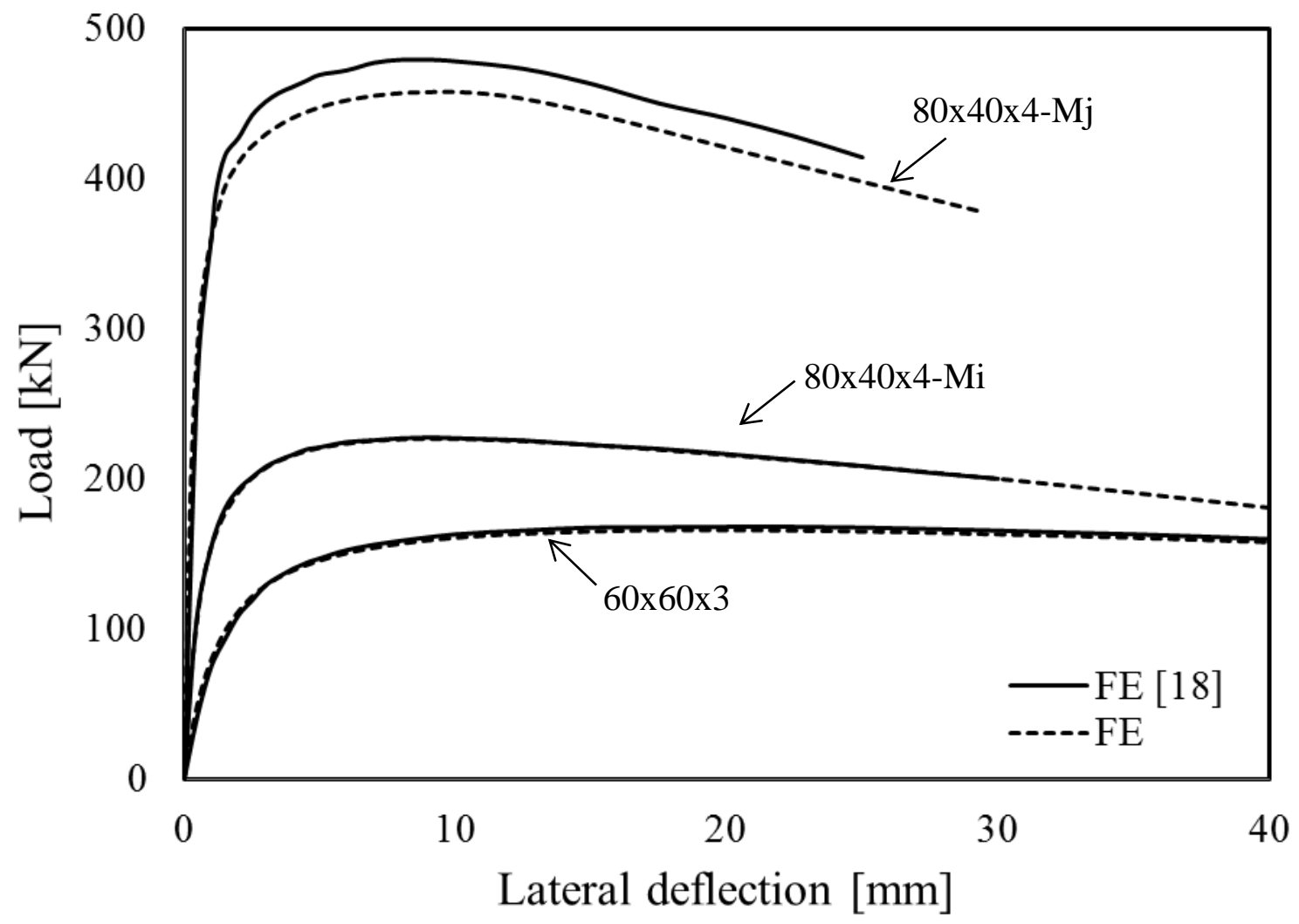

Figure 2. Comparison between reported and conducted FE models for RHS and SHS subjected to flexural buckling for L/1500 imperfection amplitude, [18] 


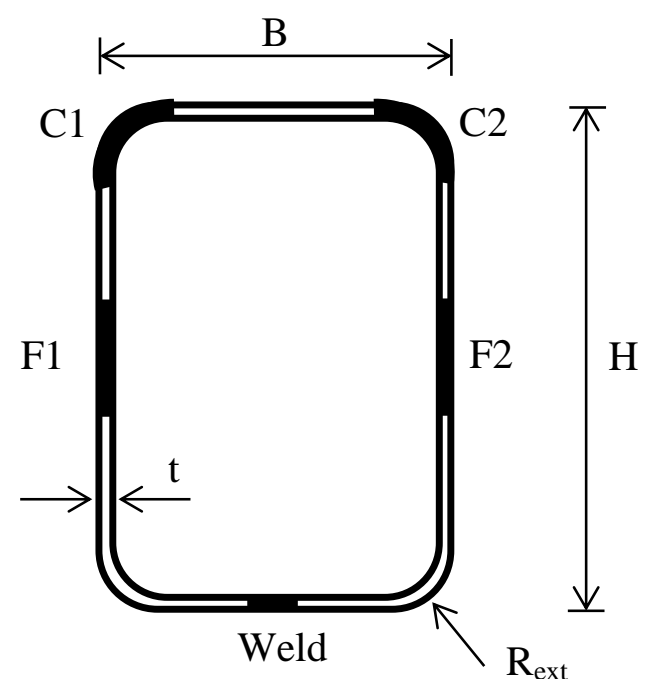

Figure 3. Location of flat and corner coupons and definition of cross section symbols.

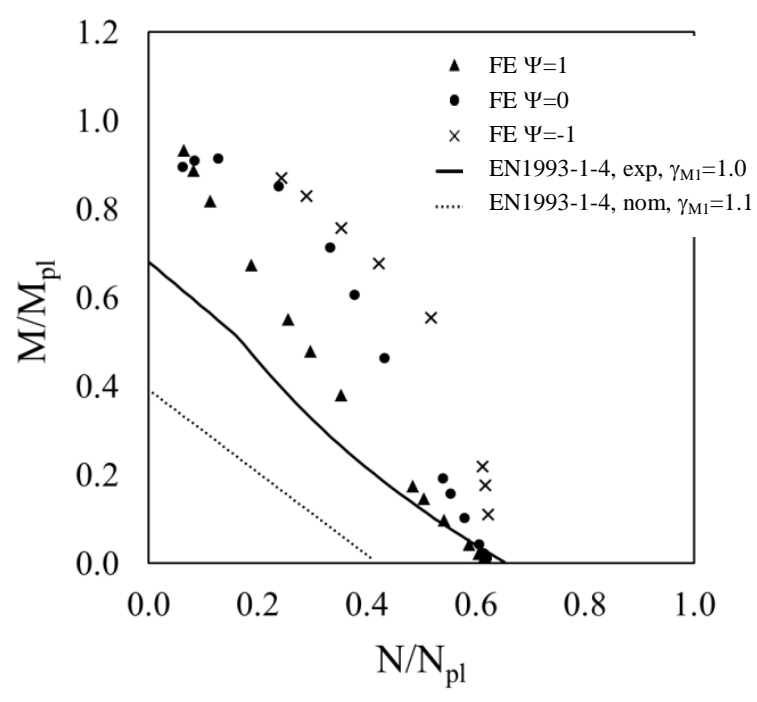

(a) Ultimate response and interaction expressions for $80 \mathrm{x} 80 \mathrm{x} 4$

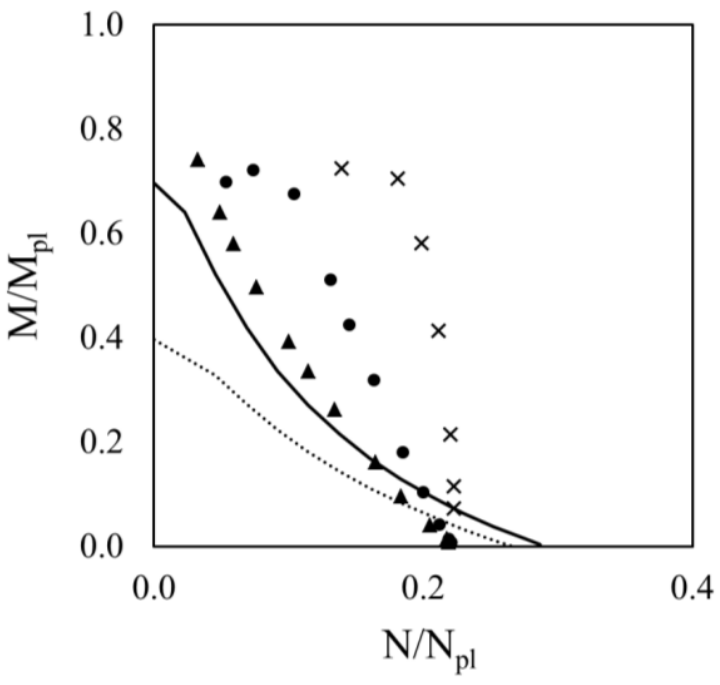

(b) Ultimate response and interaction expressions for $80 \times 40 \times 4-\mathrm{Mi}$

Figure 4. Assessment of the interaction expressions coded in EN1993-1-4 [2] for different material properties and $\gamma_{\mathrm{M} 1}$ values. 


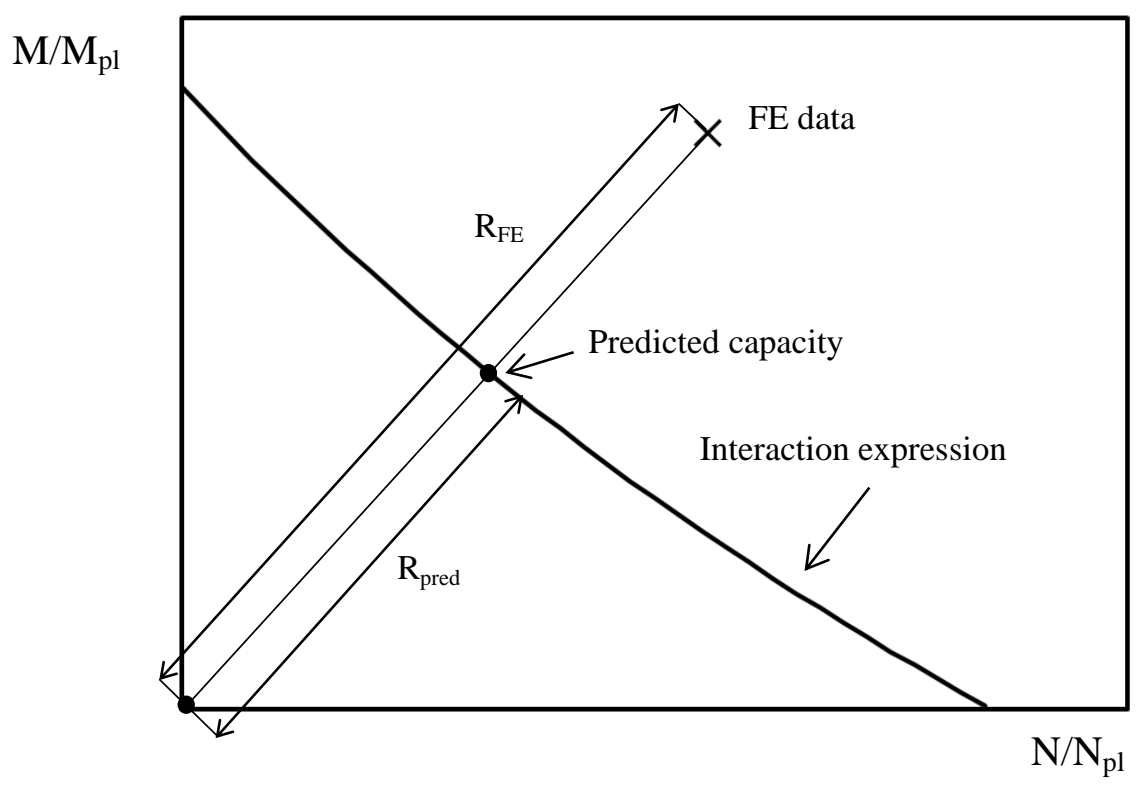

Figure 5. Graphic definition of U parameter for the assessment of design approaches.

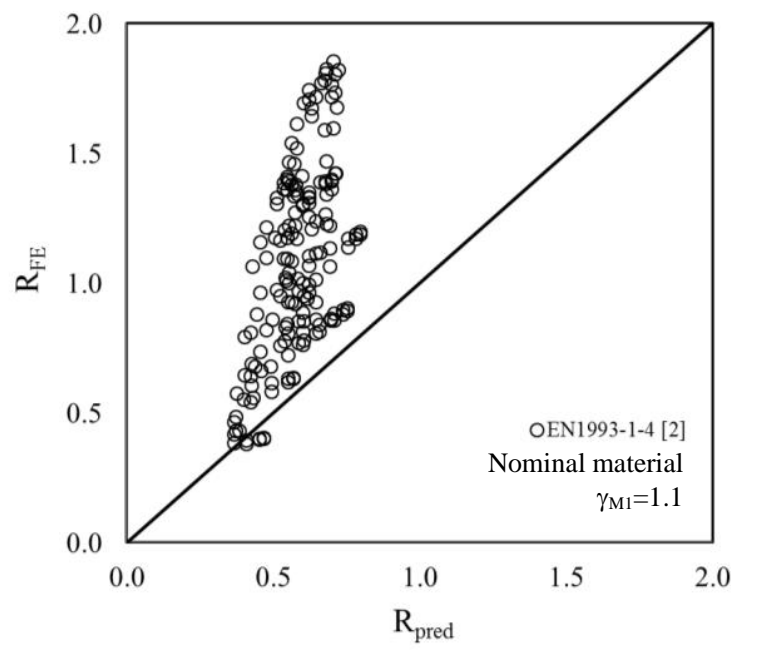

(a) Assessment considering nominal material and $\gamma_{\mathrm{M} 1}=1.1$

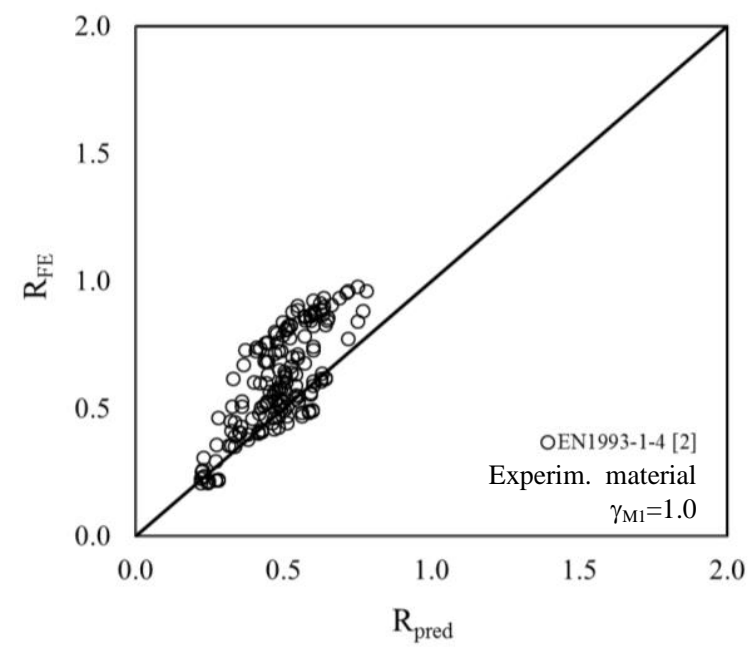

(b) Assessment considering experimental material and $\gamma_{\mathrm{M} 1}=1.0$

Figure 6. Assessment of the interaction expressions coded in EN1993-1-4 [2] for different material properties and $\gamma_{\mathrm{M} 1}$ values. 


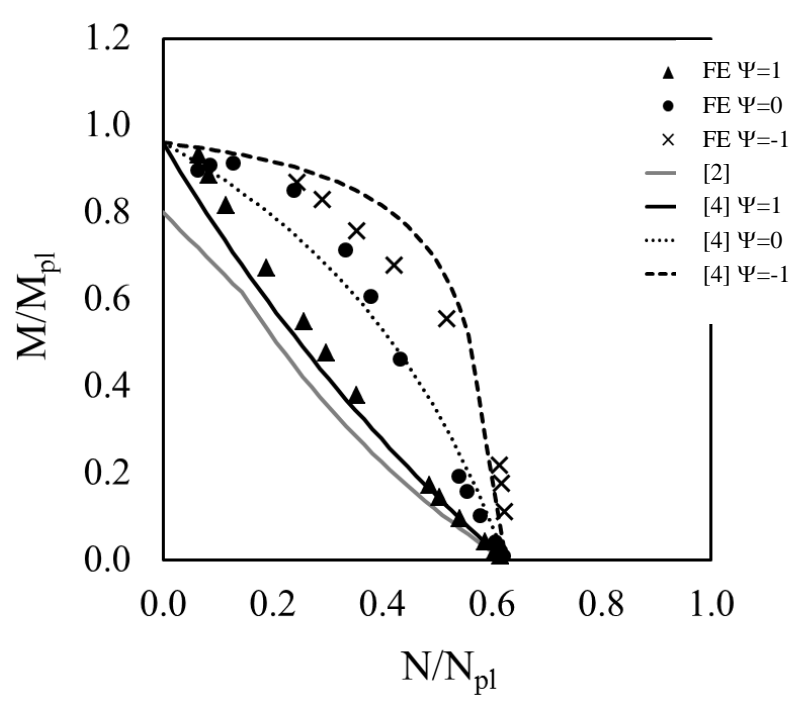

(a) [2] and [4] assessment for $80 \times 80 \times 4$

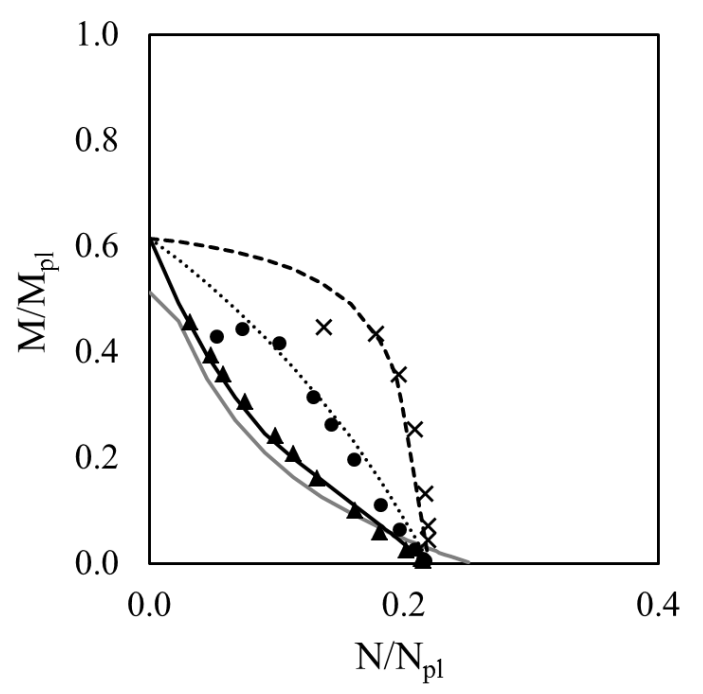

(b) [2] and [4] assessment for $80 \times 40 \times 4-M i$

Figure 7. Assessment of [2] and [4] interaction approaches for 80x80x4 and 80x40x4-Mi.

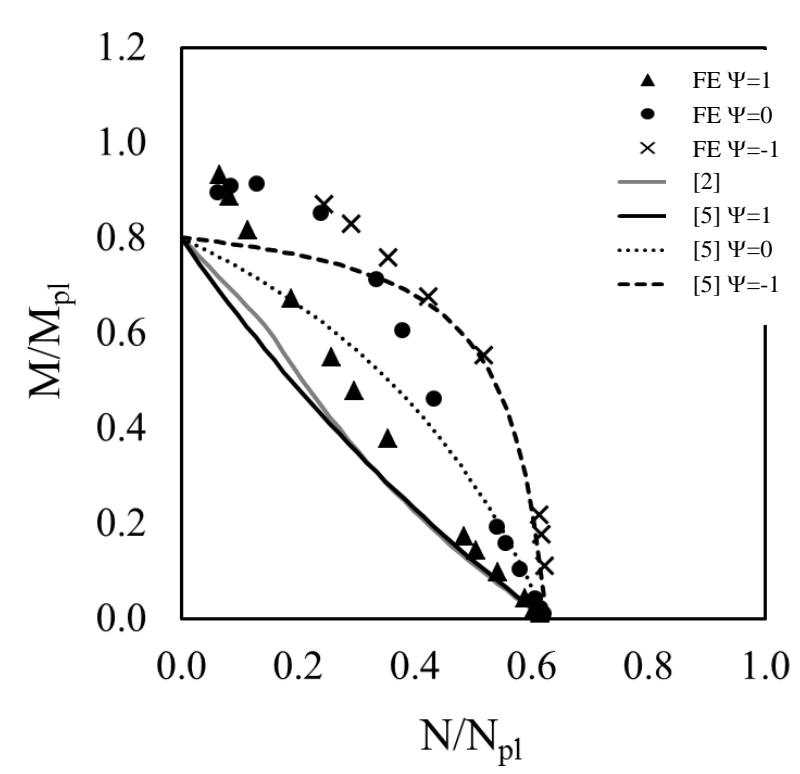

(a) [2] and [5] assessment for $80 \times 80 \times 4$

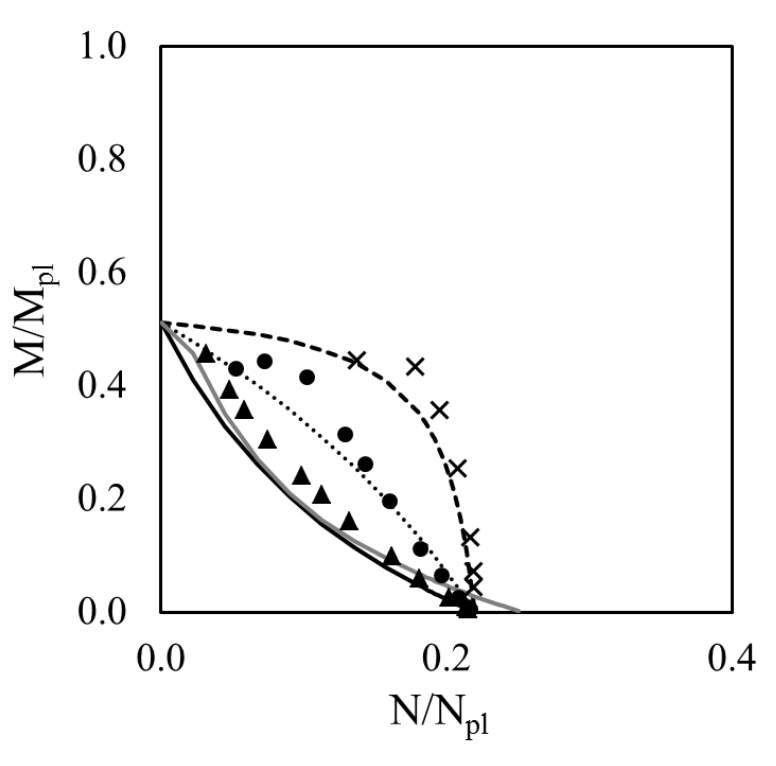

(b) [2] and [5] assessment for $80 \times 40 \times 4-\mathrm{Mi}$

Figure 8. Assessment of [2] and [5] interaction approaches for 80x80x4 and 80x40x4-Mi. 


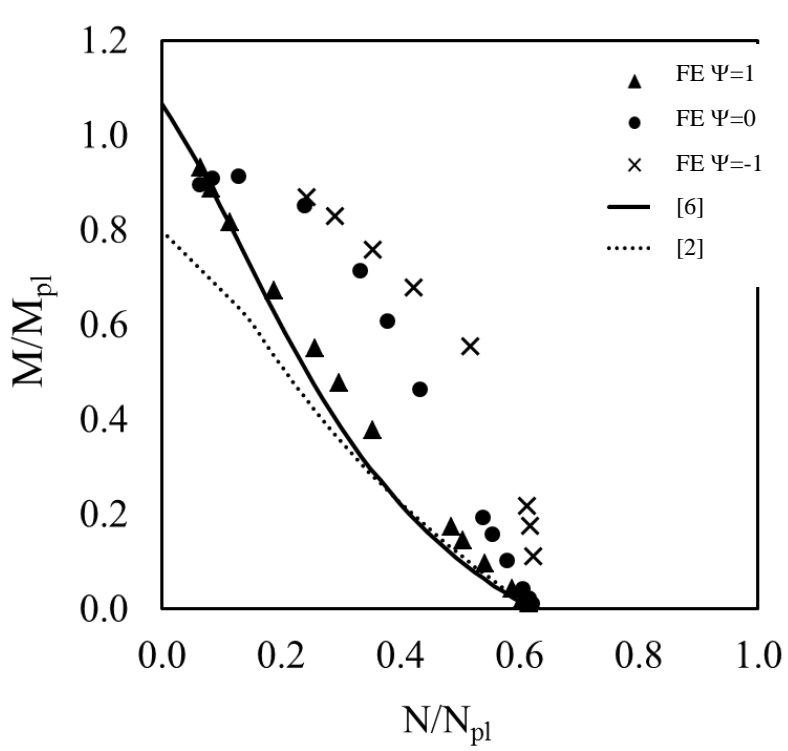

(a) [2] and [6] assessment for $80 \times 80 \times 4$

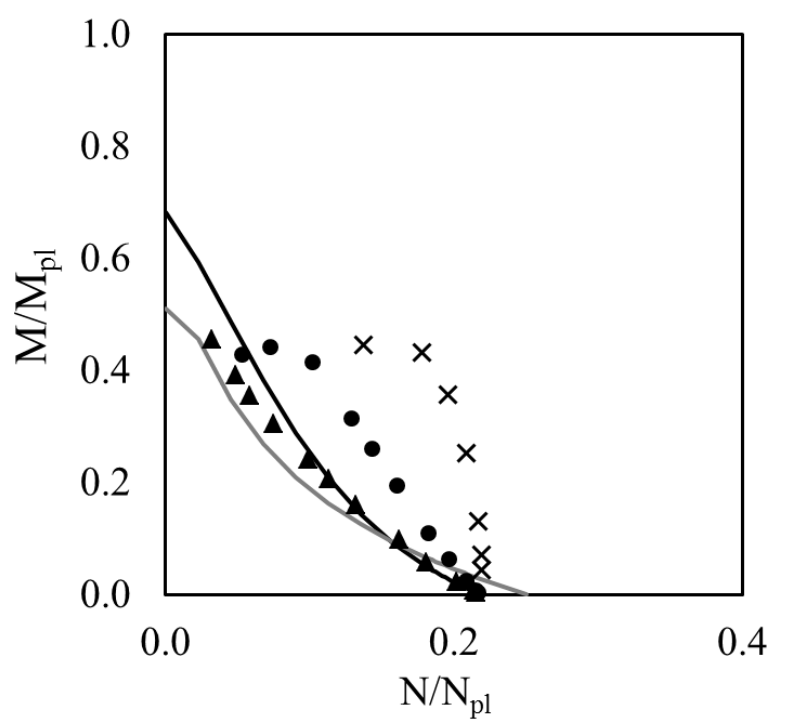

(b) [2] and [6] assessment for $80 x 40 x 4-M i$

Figure 9. Assessment of [2] and [6] interaction approaches for 80x80x4 and 80x40x4-Mi. 


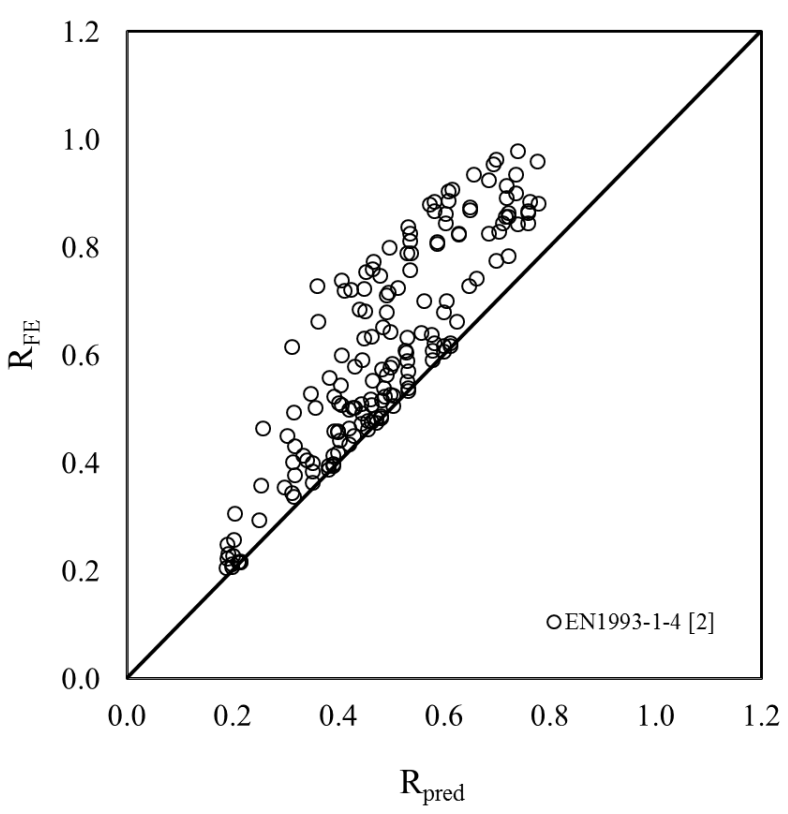

(a) Assessment of the approach coded in EN1993-1-4 [2]

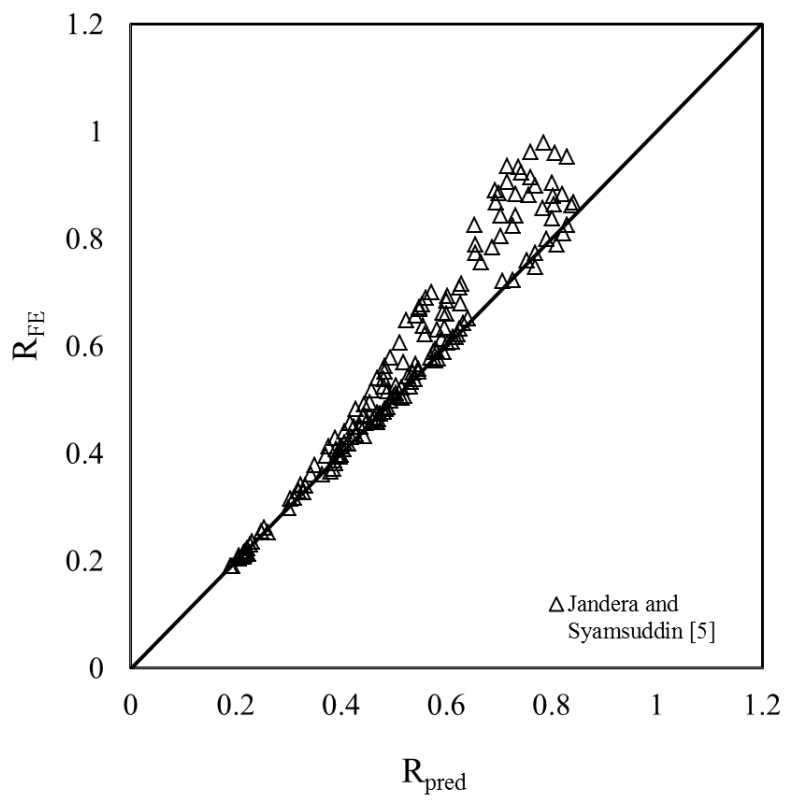

(c) Assessment of the approach proposed in Jandera and Syamsuddin [5].

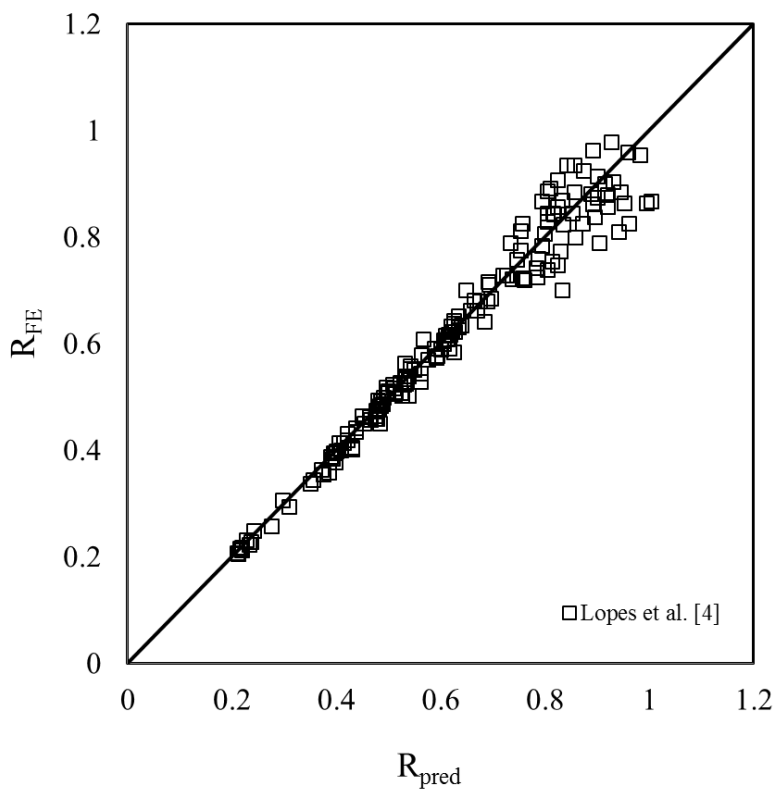

(b) Assessment of the approach proposed in Lopes et al. [4]

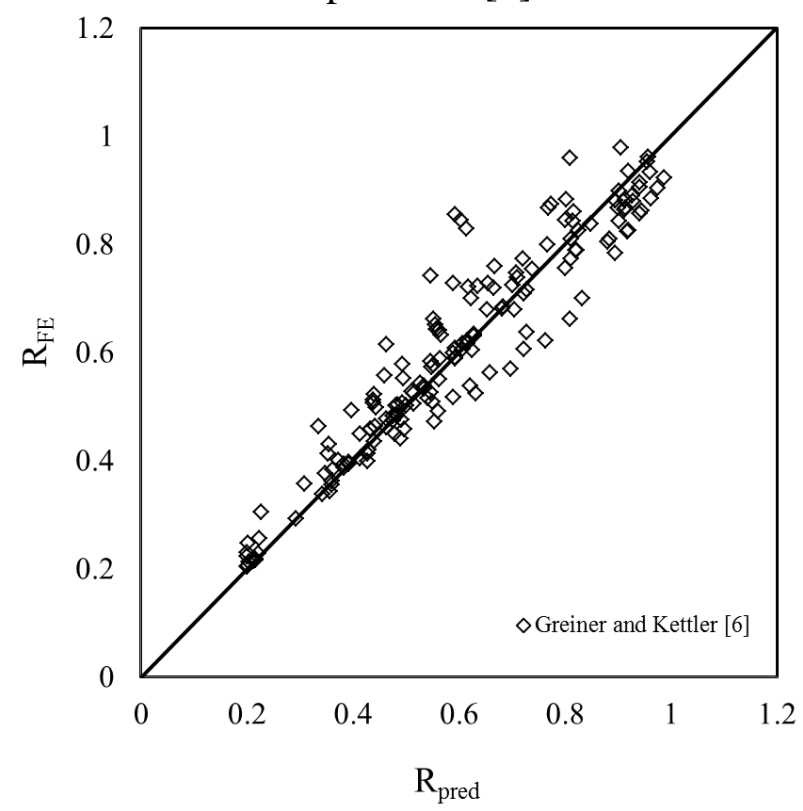

(d) Assessment of the approach proposed in Greiner and Kettler [6].

Figure 10. Assessment of the interaction expressions in EN1993-1-4 [2] and proposed by Lopes et al. [4], Jandera and Syamsuddin [5] and Greiner and Kettler [6]. 


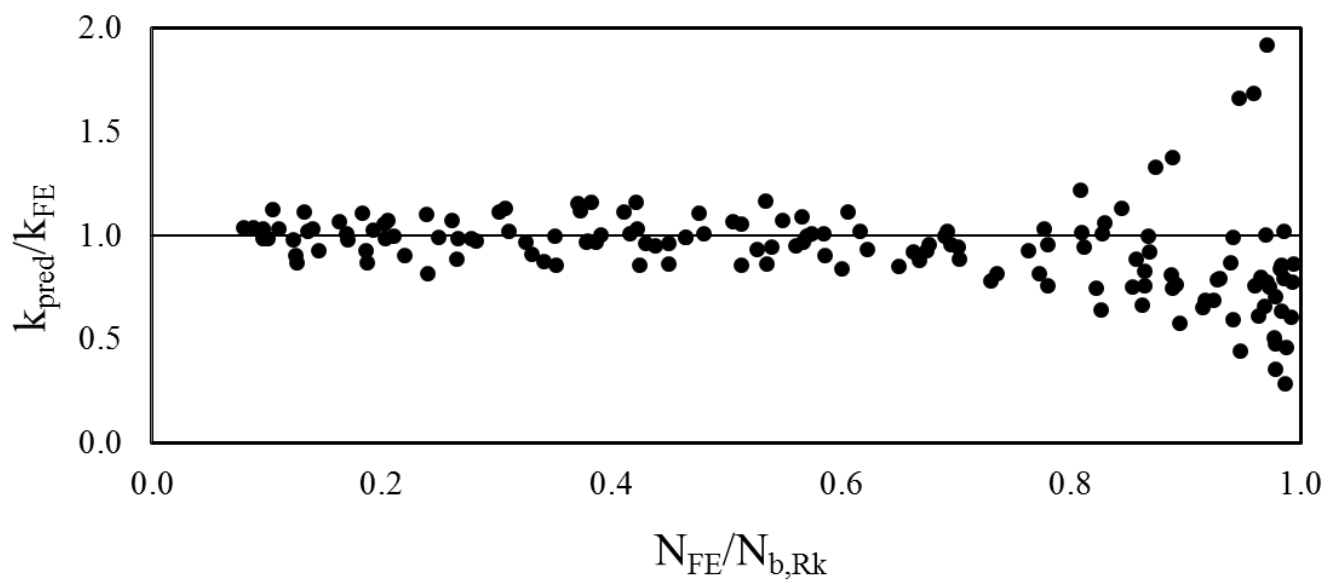

Figure 11. Assessment of Eq. (18) for different $\mathrm{N}_{\mathrm{FE}} / \mathrm{N}_{\mathrm{b}, \mathrm{Rk}}$ ratios.

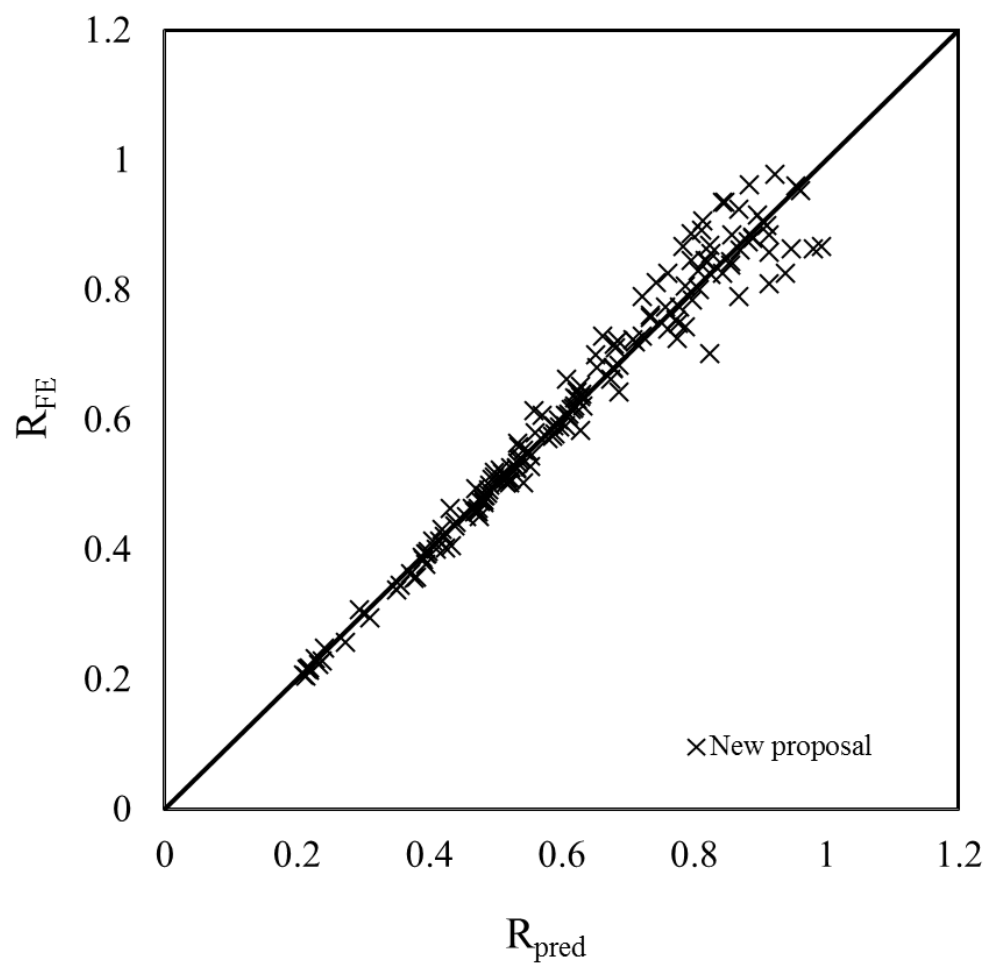

Figure 12. Assessment of the new approach. 
Table 1. Comparison between experimental and FE results for stainless steel columns subjected to flexural buckling.

\begin{tabular}{|c|c|c|c|c|c|c|c|c|c|}
\hline \multirow{4}{*}{ Cross-section } & \multicolumn{8}{|c|}{ Initial global imperfection amplitude $\mathrm{e}_{0}$} & \multirow{4}{*}{ Source } \\
\hline & \multicolumn{2}{|c|}{$\mathrm{L} / 500$} & \multicolumn{2}{|c|}{$\mathrm{L} / 1000$} & \multicolumn{2}{|c|}{$\mathrm{L} / 1500$} & \multicolumn{2}{|c|}{$\mathrm{L} / 2000$} & \\
\hline & $\mathrm{F}_{\mathrm{u}, \mathrm{FE}}$ & $\mathrm{d}_{\mathrm{u}, \mathrm{FE}}$ & $\mathrm{F}_{\mathrm{u}, \mathrm{FE}}$ & $\mathrm{d}_{\mathrm{u}, \mathrm{FE}}$ & $\mathrm{F}_{\mathrm{u}, \mathrm{FE}}$ & $\mathrm{d}_{\mathrm{u}, \mathrm{FE}}$ & $\mathrm{F}_{\mathrm{u}, \mathrm{FE}}$ & $\mathrm{d}_{\mathrm{u}, \mathrm{FE}}$ & \\
\hline & $\overline{\mathrm{F}_{\mathrm{u}, \exp }}$ & $\overline{\mathrm{d}_{\mathrm{u}, \exp }}$ & $\overline{F_{u, \exp }}$ & $\overline{\mathrm{d}_{\mathrm{u}, \exp }}$ & $\overline{\mathrm{F}_{\mathrm{u}, \exp }}$ & $\overline{\mathrm{d}_{\mathrm{u}, \exp }}$ & $\overline{\mathrm{F}_{\mathrm{u}, \exp }}$ & $\overline{\mathrm{d}_{\mathrm{u}, \exp }}$ & \\
\hline $60 \times 60 \times 3$ & 0.93 & 1.56 & 0.99 & 1.09 & 1.02 & 1.09 & 1.04 & 0.77 & [18] \\
\hline $80 \times 40 x 4-M j$ & 0.85 & 1.63 & 0.89 & 1.40 & 0.91 & 1.14 & 0.92 & 1.26 & {$[18]$} \\
\hline 80x40x4-Mi & 0.87 & 1.63 & 1.08 & 1.10 & 0.95 & 0.88 & 0.97 & 0.80 & [18] \\
\hline $80 \times 80 \times 3$ & 0.92 & 1.20 & 0.96 & 1.01 & 0.99 & 0.96 & 0.99 & 0.86 & [19] \\
\hline Mean & 0.89 & 1.51 & 0.98 & 1.15 & "0.97 & 1.02 & 0.98 & 0.92 & \\
\hline $\mathrm{COV}$. & 0.043 & 0.137 & 0.080 & 0.149 & 0.049 & 0.117 & 0.051 & 0.247 & \\
\hline
\end{tabular}

Table 2. Average measured dimensions.

\begin{tabular}{cccccc}
\hline & $\begin{array}{c}\mathrm{L} \\
{[\mathrm{mm}]}\end{array}$ & $\begin{array}{c}\mathrm{H} \\
{[\mathrm{mm}]}\end{array}$ & $\begin{array}{c}\mathrm{B} \\
{[\mathrm{mm}]}\end{array}$ & $\begin{array}{c}\mathrm{t} \\
{[\mathrm{mm}]}\end{array}$ & $\begin{array}{c}\mathrm{R}_{\text {ext }} \\
{[\mathrm{mm}]}\end{array}$ \\
\hline \hline 80x80x4 & 1495 & 80.2 & 79.6 & 3.9 & 6.9 \\
80x40x4 & 1500 & 80.1 & 39.9 & 3.8 & 6.8 \\
70x50x2 & 1500 & 70.1 & 49.7 & 1.9 & 4.4 \\
\hline \hline
\end{tabular}

Table 3. Average tensile test results for flat $(\mathrm{F})$ and corner $(\mathrm{C})$ parts.

\begin{tabular}{cccccccccc}
\hline \hline & $\begin{array}{c}\mathrm{E} \\
{[\mathrm{MPa}]}\end{array}$ & $\begin{array}{c}\sigma_{0.05} \\
{[\mathrm{MPa}]}\end{array}$ & $\begin{array}{c}\sigma_{0.2} \\
{[\mathrm{MPa}]}\end{array}$ & $\begin{array}{c}\sigma_{\mathrm{u}} \\
{[\mathrm{MPa}]}\end{array}$ & $\begin{array}{c}\varepsilon_{\mathrm{u}} \\
{[\%]}\end{array}$ & $\begin{array}{c}\varepsilon_{\mathrm{u}, \mathrm{pred}} \\
{[\%]}\end{array}$ & $\begin{array}{c}\varepsilon_{\mathrm{f}} \\
{[\%]}\end{array}$ & $\mathrm{n}$ & $\mathrm{m}$ \\
\hline \hline $80 \times 80 \times 4-\mathrm{F}$ & 173992 & 465 & 521 & 559 & 8.2 & 6.8 & 21.7 & 12.4 & 2.3 \\
$80 \times 80 \times 4-\mathrm{C}$ & 164834 & 441 & 576 & 644 & 1.0 & 10.6 & 7.8 & 5.0 & 5.4 \\
\hline $80 \times 40 \times 4-\mathrm{F}$ & 181632 & 467 & 507 & 519 & 3.6 & 2.3 & 20.9 & 16.4 & 2.5 \\
$80 \times 40 \times 4-\mathrm{C}$ & 168684 & 434 & 558 & 601 & 0.9 & 7.2 & 7.0 & 5.9 & 4.5 \\
\hline $70 \times 50 \times 2-\mathrm{F}$ & 179568 & 381 & 418 & 480 & 13.7 & 12.9 & 26.7 & 15.3 & 2.4 \\
$70 \times 50 \times 2-\mathrm{C}$ & 161026 & 466 & 552 & 574 & 1.1 & 3.8 & 6.5 & 8.0 & 4.6 \\
\hline \hline
\end{tabular}

Table 4. Weighted tensile material properties.

\begin{tabular}{cccccccc}
\hline \hline & $\begin{array}{c}\mathrm{E} \\
{[\mathrm{MPa}]}\end{array}$ & $\begin{array}{c}\sigma_{0.05} \\
{[\mathrm{MPa}]}\end{array}$ & $\begin{array}{c}\sigma_{0.2} \\
{[\mathrm{MPa}]}\end{array}$ & $\begin{array}{c}\sigma_{\mathrm{u}} \\
{[\mathrm{MPa}]}\end{array}$ & $\begin{array}{c}\varepsilon_{\mathrm{u}} \\
{[\%]}\end{array}$ & $\mathrm{n}$ & $\mathrm{m}$ \\
\hline \hline 80x80x4 & 172391 & 456 & 540 & 563 & 7.8 & 8.8 & 2.6 \\
$80 \times 40 \times 4$ & 178503 & 451 & 510 & 524 & 3.5 & 12.9 & 2.7 \\
$70 \times 50 \times 2$ & 175162 & 400 & 430 & 488 & 12.6 & 14.7 & 2.4 \\
\hline $\begin{array}{c}\text { Nominal } \\
\text { EN1993-1-4 }\end{array}$ & 220000 & -- & 280 & 450 & 38 & 7.0 & 1.6 \\
\hline \hline
\end{tabular}


Table 5. Assessment of flexural buckling resistance of ferritic stainless steel columns for different approaches, $\gamma_{\mathrm{M} 1}$ values and material properties.

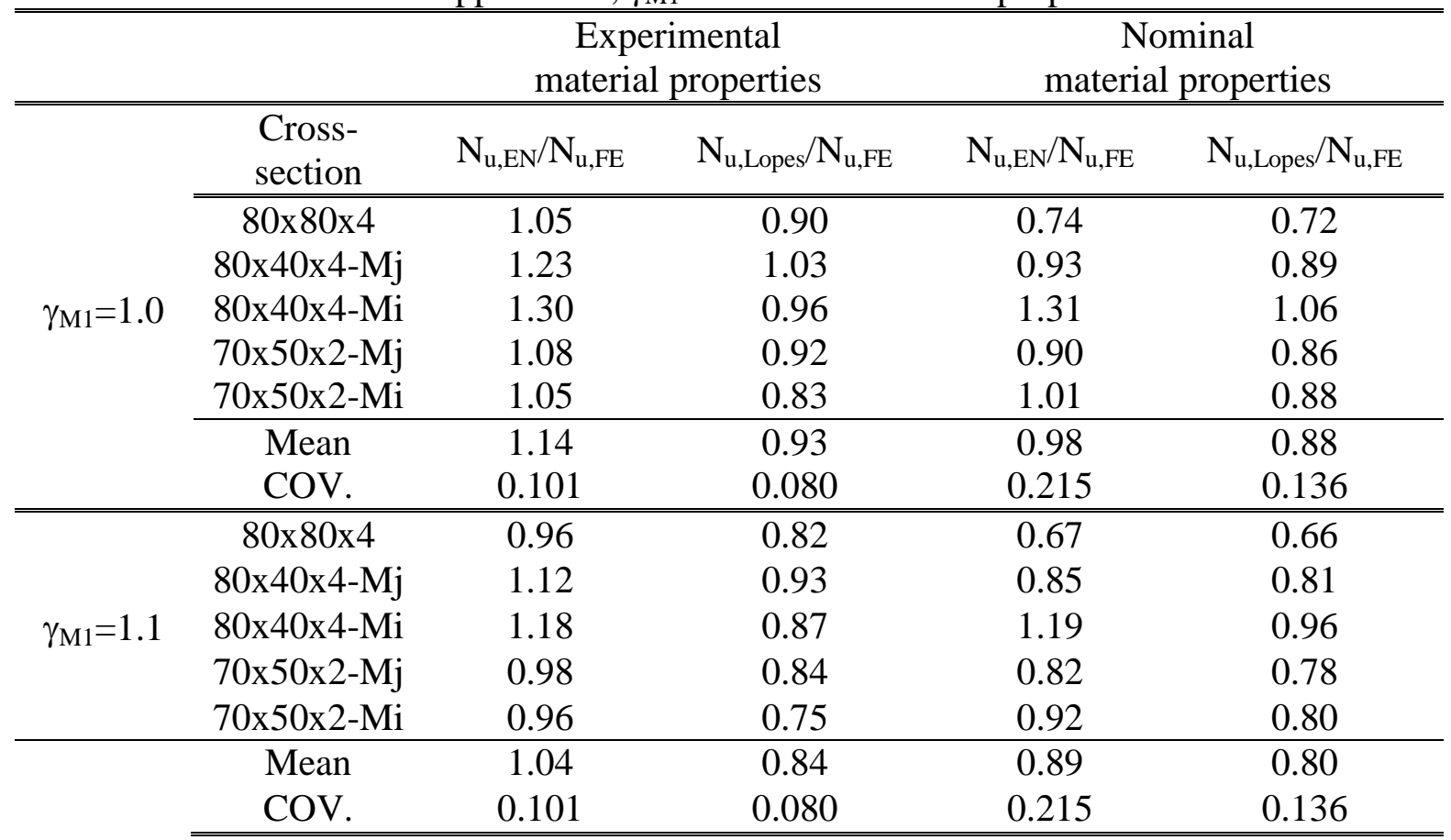

Table 6. Assessment of EN1993-1-4 design approach considering different material properties for ferritic RHS and SHS beam-columns

\begin{tabular}{|c|c|c|c|}
\hline \multirow{2}{*}{$\begin{array}{l}\text { Cross- } \\
\text { section }\end{array}$} & \multirow{2}{*}{$\begin{array}{c}\text { Bending } \\
\text { moment } \\
\text { distribution }\end{array}$} & \multicolumn{2}{|c|}{$\begin{array}{l}\text { U ratios for EN1993-1-4 [2] approach } \\
\text { Eqs.(5)-(6) }\end{array}$} \\
\hline & & $\begin{array}{c}\text { Nominal material } \\
\gamma_{\mathrm{M} 1}=1.1\end{array}$ & $\begin{array}{c}\text { Experimental material } \\
\gamma_{\mathrm{M} 1}=1.0\end{array}$ \\
\hline \multirow{3}{*}{$80 \times 80 \times 4$} & $\Psi=1$ & 0.55 & 0.87 \\
\hline & $\Psi=0$ & 0.50 & 0.79 \\
\hline & $\Psi=-1$ & 0.43 & 0.67 \\
\hline \multirow{3}{*}{$80 \times 40 \times 4-M j$} & $\Psi=1$ & 0.66 & 1.06 \\
\hline & $\Psi=0$ & 0.56 & 0.91 \\
\hline & $\Psi=-1$ & 0.52 & 0.82 \\
\hline \multirow{3}{*}{$80 \times 40 \times 4-M i$} & $\Psi=1$ & 0.81 & 1.00 \\
\hline & $\Psi=0$ & 0.75 & 0.90 \\
\hline & $\Psi=-1$ & 0.59 & 0.70 \\
\hline \multirow{3}{*}{$70 \times 50 \times 2-\mathrm{Mj}$} & $\Psi=1$ & 0.66 & 0.87 \\
\hline & $\Psi=0$ & 0.59 & 0.78 \\
\hline & $\Psi=-1$ & 0.50 & 0.67 \\
\hline \multirow{5}{*}{$70 \times 50 \times 2-\mathrm{Mi}$} & $\Psi=1$ & 0.63 & 0.82 \\
\hline & $\Psi=0$ & 0.59 & 0.74 \\
\hline & $\Psi=-1$ & 0.46 & 0.61 \\
\hline & $\overline{\text { Mean }}$ & 0.59 & 0.83 \\
\hline & COV. & 0.313 & 0.226 \\
\hline
\end{tabular}


Table 7. Assessment of different design approaches for ferritic RHS beam-columns

\begin{tabular}{cccccc}
\hline \hline \multirow{2}{*}{$\begin{array}{c}\text { Cross- } \\
\text { section }\end{array}$} & $\begin{array}{c}\text { Bending } \\
\text { moment } \\
\text { distribution }\end{array}$ & $\begin{array}{c}\text { EN1993-1-4 } \\
{[2]}\end{array}$ & $\begin{array}{c}\text { Lopes et al. } \\
{[4]}\end{array}$ & $\begin{array}{c}\text { Jandera and } \\
\text { Syamsuddin } \\
{[5]}\end{array}$ & $\begin{array}{c}\text { Greiner and } \\
\text { Kettler [6] }\end{array}$ \\
\hline \hline \multirow{3}{*}{$80 \times 80 \times 4$} & $\Psi=1$ & 0.90 & 0.96 & 0.89 & 1.07 \\
& $\Psi=0$ & 0.82 & 0.99 & 0.92 & 1.01 \\
& $\Psi=-1$ & 0.69 & 1.02 & 0.96 & 0.95 \\
\hline \multirow{3}{*}{$80 \times 40 \times 4-\mathrm{Mj}$} & $\Psi=1$ & 0.93 & 0.99 & 0.92 & 1.04 \\
& $\Psi=0$ & 0.80 & 0.98 & 0.91 & 0.98 \\
& $\Psi=-1$ & 0.72 & 1.01 & 0.97 & 0.90 \\
\hline \multirow{3}{*}{ 70x40x4-Mi } & $\Psi=1$ & 0.90 & 1.05 & 0.97 & 1.10 \\
& $\Psi=0$ & 0.80 & 1.06 & 0.98 & 1.02 \\
& $\Psi=-1$ & 0.63 & 1.00 & 1.00 & 0.87 \\
\hline \multirow{3}{*}{$70 \times 50 \times 2-\mathrm{Mi}-\mathrm{Mj}$} & $\Psi=1$ & 0.94 & 1.01 & 0.93 & 1.12 \\
& $\Psi=0$ & 0.83 & 1.03 & 0.95 & 1.03 \\
& $\Psi=-1$ & 0.75 & 1.10 & 0.76 & 0.85 \\
\hline \hline & $\Psi=1$ & 0.90 & 1.10 & 0.92 & 1.09 \\
& $\Psi=0$ & 0.79 & 1.01 & 0.94 & 1.02 \\
& $\Psi=-1$ & 0.67 & 1.02 & 0.95 & 0.96 \\
\hline & Mean & 0.82 & 1.01 & 0.94 & 0.98 \\
& $\mathrm{COV}$. & 0.153 & 0.050 & 0.076 & 0.104 \\
\hline
\end{tabular}

Table 8. Assessment of the new proposal for ferritic RHS beam-columns.

\begin{tabular}{cccccc}
\hline \hline \multirow{2}{*}{$\begin{array}{c}\text { Bending } \\
\text { moment }\end{array}$} & \multicolumn{5}{c}{$\mathrm{U}$ ratios for the new proposal Eq. (18) } \\
\cline { 2 - 6 } distribution & $80 \times 80 \times 4$ & $80 \times 40 \times 4-\mathrm{Mj}$ & $80 \times 40 \times 4-\mathrm{Mi}$ & 70x50x2-Mj & 70x50x2-Mi \\
\hline \hline$\Psi=1$ & 0.96 & 1.00 & 1.05 & 1.02 & 1.01 \\
$\Psi=0$ & 0.98 & 0.98 & 1.05 & 1.02 & 1.00 \\
$\Psi=-1$ & 0.99 & 0.99 & 0.96 & 1.07 & 0.99 \\
\hline \hline
\end{tabular}

All cross-sections and bending moment distributions

\begin{tabular}{cc}
\hline Mean & 1.00 \\
COV. & 0.048 \\
\hline
\end{tabular}

